\title{
ASPECTOS DA PREVALÊNCIA DE ENTEROPARASITOSES EM CRIANÇAS DO BAIRRO SANTO ANDRÉ, VITÓRIA-ES
}

\section{WILSON DENADAI}

Dissertação de mestrado apresentada na área de concentração de serviços de saúde da Faculdade de Saúde Pública da Universidade de São Paulo para obtençāo do Grau de Mestre.

Área de Concentração: Serviços de Saúde Pública

Orientador: Prof. Dr. Glavur Rogério Matté 


\section{AGRADECIMENTOS}

Ao Prof. Antônio Claudino de Jesus e a Prof.Dr. Selma Blom Margotto, por serem incentivadores e referência de profissionalismo e cultura.

Ao Prof. Dr. João Alvécio Sossai, pela concreta contribuição no processo de construção da dissertação.

À instituição FAESA que disponibilizou suas dependências e laboratórios.

À SEMUS de Vitória, em especial para a Dr. Fátima Silva e a Andréa Coelho Vidigal que acolheram o projeto e o viabilizaram junto à prefeitura e unidade de saúde.

Aos colaboradores da pesquisa de campo e das técnicas laboratoriais

Ariele Spanhol Rosseto

Bruno S C Merísio

Carolina Fernandes Scarpat

Carolini Luca Poppi

David Gonçalves Borges

Diego Moraes de Resende Muchuli

Felipe Addum

Gracielle Meire Libório

Henrique F Ferreira

Kamila Cristina Lima da Fonseca

Karina de Souza Gomes

Luana Gardioli Vieira

Luciana Araújo Abreu

Marcus Vinicius Pacheco

Michela Nascimento Mello

Naime Thompson

Nivea Denadai

Paula Roberta Calais

Rakel Garbaletto de Ávila

Rander Silva Bello

Ricardo Domelas Ribeiro

Thadeu Leite Justo

Thais Mendes Luppi da Silva

Aos Técnicos laboratoriais

Ludmilla Prette

Amanda Soanny 


\section{RESUMO}

Denadai W. Aspectos da prevalência de enteroparasitoses em crianças do bairro Santo André, Vitória-ES. São Paulo; 2004. Dissertação de Mestrado - Faculdade de Saúde Pública da USP.

Introdução: Doenças entéricas, resultantes de infecção por parasitas, representam importante problema de saúde pública em todo mundo, intensificado principalmente em paises com maior freqüência de problemas sócio-econômicos. Objetivos: Estudar a prevalência e fatores relacionados às parasitoses intestinais, em um bairro de Vitória-ES, caracterizado por classe econômica baixa e suprido por saneamento básico. Métodos: A análise de 100 amostras de fezes de crianças de 1 a 4 anos de idade e de 60 plantas de alface foi realizada através do método de sedimentação. As informações sobre as crianças foram obtidas através de entrevista com os pais. Resultados: Das 100 amostras de fezes 40 (40\%) apresentaram resultado positivo para parasitas intestinais. Os parasitas observados nas amostras de fezes foram $G$. duodenalis (24\%), A. lumbricoides (15\%), $T$. trichiura $(5 \%)$, E. histolytica $(3 \%)$, S. stercoralis $(3 \%), H$. nana $(1 \%)$, ancilostomídeos (1\%) e E. vermicularis (1\%). A prevalência de parasitas entéricos em amostras de alface foi de $23,3 \%$, da seguinte forma: Strongyloides sp (10\%), Giardia sp (8,3\%), Ascaris sp (3,3\%) e Trichuris sp $(1,6 \%)$. Conclusão: Embora a área estudada seja provida de saneamento básico, a alta prevalência de parasitas entéricos, observada em crianças e 
em plantas de alface, sugere que a intensificação no diagnóstico e tratamento da população suscetivel, associada a campanhas de educação em saúde e melhorias nos serviços de vigilância em saúde, pode contribuir para a redução dos casos positivos.

Descritores: Parasitoses Intestinais. Contaminação de Hortaliças. Saneamento Básico 


\section{SUMMARY}

Denadai W. Prevalence aspects of intestinal parasitosis in Santo André district's children, Vitória-ES. São Paulo; 2005. Master's Dissertation College of Public Health of USP.

Introduction: Intestinal disease resulting from infection with enteric parasites constitutes an important worldwide public health issue mainly in countries with social and economic problems. Objectives: To study the prevalence and related factors of intestinal parasitic disease in a neighborhood area of Vitória-ES characterized by its low economic status and supplied by basic sanitation. Methods: Analyses of 100 fecal samples from children within 1 to 4 years of age and 60 lettuce plants were carried out by the sedimentation method and information on the children was obtained by interviewing parents. Results: From 100 fecal samples $40 \%$ showed positive results for intestinal parasites. G. duodenalis was observed in $24 \%$ of fecal samples, $A$. lumbricoides in $15 \%, T$. trichiura in $5 \%, E$. histolytica in $3 \%, S$. stercoralis in $3 \%, H$. nana in $1 \%$, ancylostomids in $1 \%$, and $E$. vermicularis in $1 \%$. The prevalence of enteric parasites in lettuce samples was $23.3 \%$ as follow Strongyloides sp (10\%), Giardia sp (8,3\%), Ascaris sp (3,3\%) and Trichuris sp $(1,6 \%)$. Conclusion: Although the studied area is provided with basic sanitation, the high prevalence of enteric parasites observed in children and in lettuce plants suggests that intensified diagnosis and treatment in that susceptible population associated with health educative campaigns and 
improvement of health surveillance would contribute to the reduction of positive cases.

Key Terms: Intestinal Parasites. Contamination of Vegetables. Basic Sanitation. 


\section{ÍNDICE}



1.1. Características gerais das enteroparasitoses....................................

1.2. Enteroparasitoses no globo

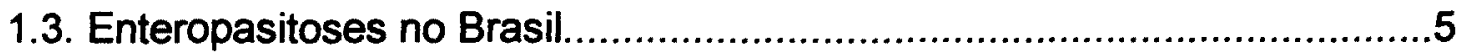

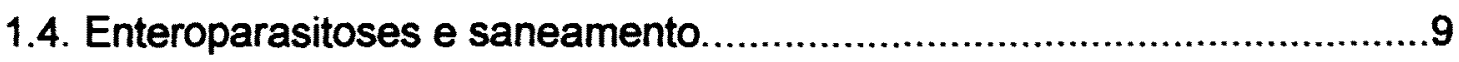

1.5. Enteroparasitoses e condiçōes socioeconômicas...................................10

1.6. Enteroparasitoses e hortaliças.....................................................12

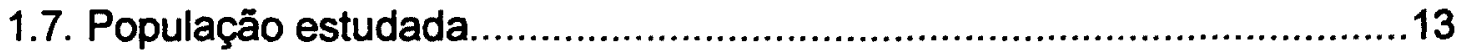

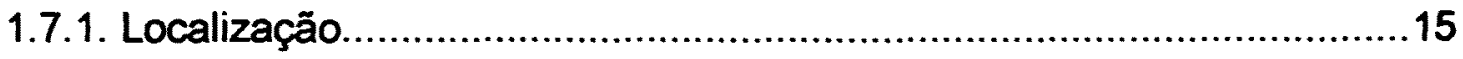

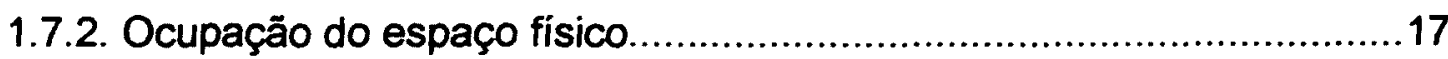

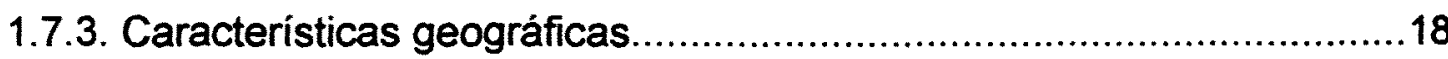

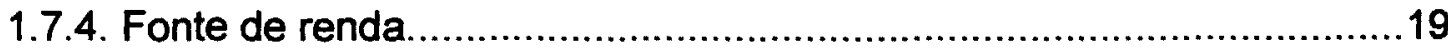

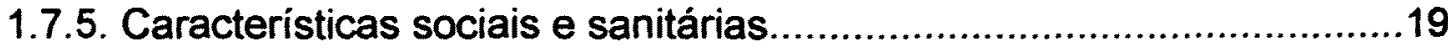

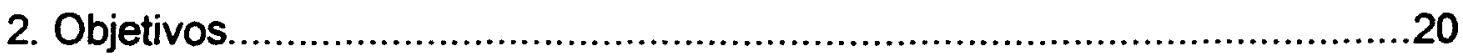

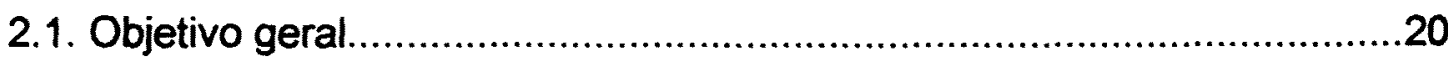

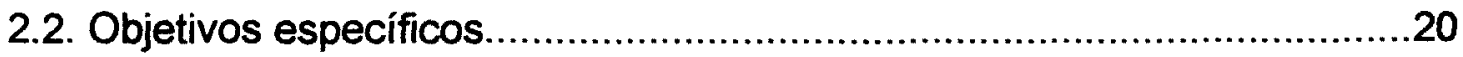

3. Metodologia

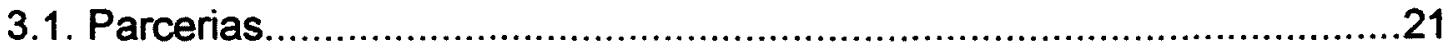




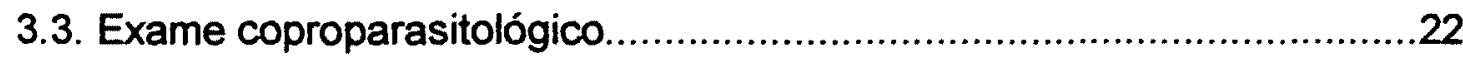

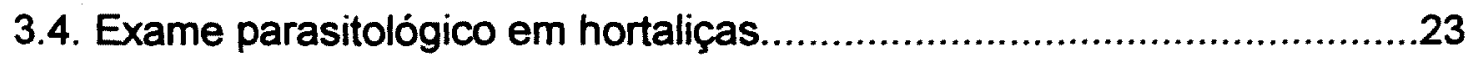

4. Resultados

5. Discussão



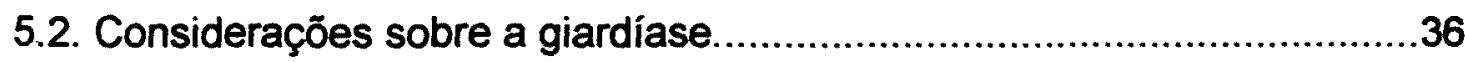

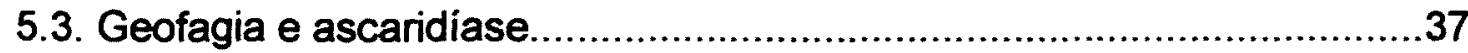

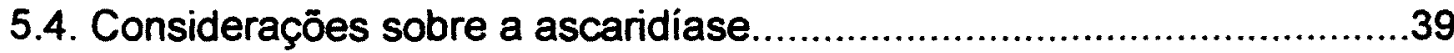

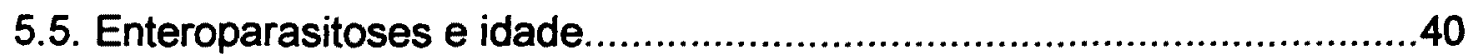

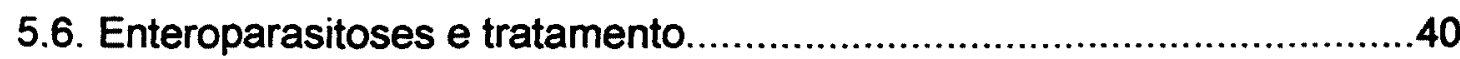

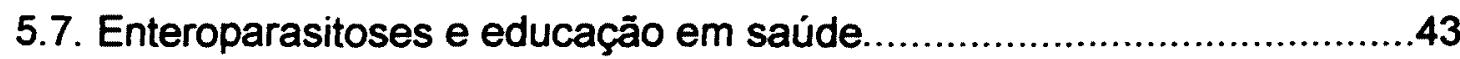

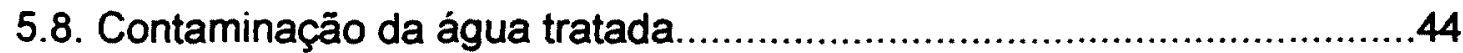

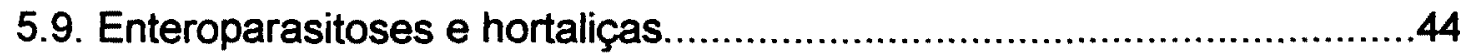

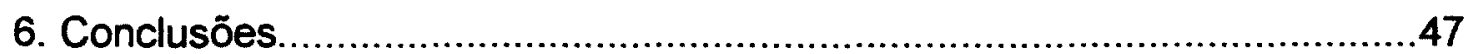

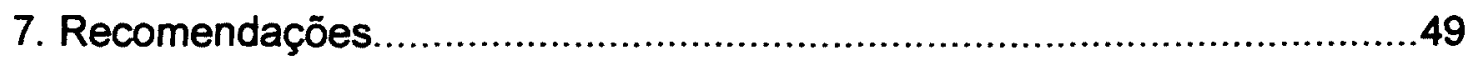

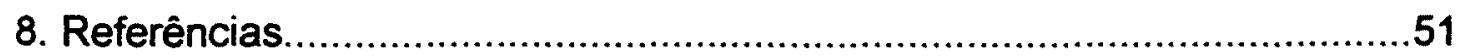

9. Anexos 


\section{ÍNDICE DE FIGURAS}

Figura 1 - Cata do lixo no bairro Santo André, Vitória-ES.

Figura 2 - Rua do bairro Santo André, Vitória-ES (2004). .15

Figura 3 - Mapa da região da grande vitória com indicação da localização do bairro Santo André. 16

Figura 4 - Vista aérea do bairro Santo André, Vitória-ES, indicado entre as faixas escuras (no centro) 16

Figura 5 - Ocupação do espaço nas proximidades do bairro Santo André, Vitória-ES .17

Figura 6 - Usina de lixo localizado nas proximidades do bairro Santo André, Vitória-ES em 2003 18

Figura 7 - Casos positivos e negativos segundo o exame coproparasitológico de 100 crianças do bairro Santo André, Vitória-ES, 2004 .25 


\section{ÍNDICE DE TABELAS}

Tabela 1 - Parasitas encontrados segundo o exame coproparasitológico de 100 crianças do bairro Santo André, Vitória-ES, 2004 .26

Tabela 2 - Espécime parasitário e idade em anos segundo o exame coproparasitológico de 100 crianças do bairro Santo André, Vitória-ES, 2004. .27

Tabela 3 - Poliparasitados e idade em anos segundo 0 exame coproparasitológico de 100 crianças do bairro Santo André, Vitória-ES, 2004. .28

Tabela 4 - Prevalência, porcentagem e significância de variáveis diversas segundo exame coproparasitológico de 100 crianças do bairro Santo André, Vitória-ES, 2004 .29

Tabela 5 - Número e proporção de variáveis qualitativas entre grupos de crianças com ausência e presença de $G$. duodenalis. segundo exame coproparasitológico de 100 crianças do bairro Santo André, Vitória-ES, 2004 32

Tabela 6 - Número e proporção de variáveis qualitativas entre grupos de crianças com ausência e presença de $A$. lumbricoides, segundo exame coproparasitológico de 100 crianças do bairro Santo André, Vitória-ES, 2004 .33 
Tabela 7 - Pés de alface contaminados segundo exame parasitológico em 60 pés de alface adquiridos no comércio do bairro Santo André, Vitória-ES, 2004 .34

Tabela 8 - Freqüência dos espécimes parasitários observados nas amostras de alface contaminadas segundo exame parasitológico em 60 pés de alface adquiridos no comércio do bairro Santo André, Vitória-ES, 2004. .34 


\section{LISTA DE FIGURAS DO ANEXO}

Figura 8 - Número de parasitados e espécime parasitário segundo exame coproparasitológico em 100 crianças de Santo André, Vitória-ES, 2004 ..$e$

Figura 9 - Número de parasitados e idade em anos segundo exame coproparasitológico em 100 crianças de Santo André, VitóriaES, 2004 .e

Figura 10 - Casos positivos, negativos e última consulta médica em meses segundo exame coproparasitológico em 100 crianças de Santo André, Vitória-ES, 2004. . f

Figura 11 - Casos positivos, negativos e último tratamento medicamentoso em meses segundo exame coproparasitológico em 100 crianças de Santo André, Vitória-ES, 2004 ...

Figura 12 - Casos positivos, negativos e forma de tratamento segundo exame coproparasitológico em 100 crianças de Santo André, Vitória-ES, 2004

Figura 13 - Casos positivos, negativos e freqüência em creche segundo exame coproparasitológico em 100 crianças de Santo André, Vitória-ES, 2004. 
Figura 14 - Casos positivos, negativos e hábito de comer alface segundo exame coproparasitológico em 100 crianças de Santo André,

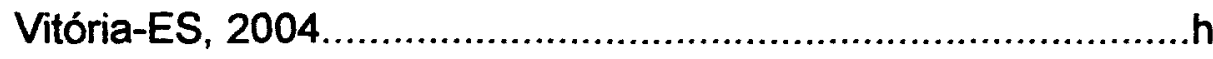

Figura 15 - Casos positivos, negativos e forma de lavar alface segundo exame coproparasitológico em 100 crianças de Santo André, Vitória-ES, 2004 ..$h$

Figura 16 - Casos positivos, negativos e presença e ausência de filtro no domicilio segundo exame coproparasitológico em 100 crianças de Santo André, Vitória-ES, 2004. . i 


\section{INTRODUÇÃO}

\subsection{Características Gerais das Enteroparasitoses}

As parasitoses intestinais são responsáveis por um grande número de sintomas e lesões, principalmente nas mucosas intestinais, näo sendo incomum o surgimento de infecçöes bacterianas secundárias que agravam ainda mais o processo mórbido, contribuindo para o óbito do enfermo (NEVES, 1995). Para REY (1991), as parasitoses intestinais têm importância pela freqüencia com que produzem deficiências orgânicas, comprometendo o desenvolvimento normal das crianças e limitando a capacidade de trabalho dos adultos, gerando em suas formas mais graves um grande número de enfermos que pesam no orçamento das famílias e no do Estado pela improdutividade, ou pelos custos da assistência médica e hospitalar que requerem.

JORGE e col. (2001) afirmam que as doenças infecciosas e parasitárias continuam a figurar nas estatísticas médico-epidemiológicas entre as principais causas de morte na América Latina e na África, sendo que, KROMBAUER e col. (1997) referem que se dá mais importância às infecções viróticas e bacterianas que as enteroparasitárias e que crianças são frequentemente contaminadas por enteroparasitas nos países em desenvolvimento.

Apesar da menor atenção dispensada às enteroparasitoses, observouse redução na prevalência. Segundo STRAKA e col. (2001), analisando resultados de exames coproparasitológicos em escolares da região de Turiec (Eslováquia Central) nos períodos de (1970-1979; 1980-1989; 1990-1999), houve redução dos casos positivos nos levantamentos mais recentes. REY em 
1991, afirmou que reduções nas taxas globais de prevalência por infecções parasitárias intestinais foram registradas nas últimas décadas, porém acrescenta que o número absoluto de casos aumentou.

\subsection{Enteroparasitoses no Globo}

Num estudo sobre as taxas mundiais de enteroparasitoses, MORRONE e col. (2004) citaram que os parasitas intestinais contaminam cerca de 2 bilhões de pessoas no mundo. PAWLOWSKI e col. (1992) estimaram a existência de até 900 milhões de contaminados por ancilostomídeos, BUNDY e COOPER, em 1998, referiram a existência de cerca de 750 milhões de contaminados por Trichuris trichiura. CROMPTON, em 1998, citou que somente o Ascaris lumbricoides contaminaria até $1 / 4$ da população mundial, distribuindo-se por mais de 150 países, a Entamoeba histolytica causaria até 500 milhões de casos e a Giardia lamblia 200 milhões.

Diversas pesquisas têm sido realizadas em todo o mundo apresentando diferentes taxas nas mais diversas regiōes do globo. De forma geral as taxas permaneceram elevadas em todos os trabalhos, assim como demonstram os resultados abaixo.

RAJESWARI e col. (1994) pesquisando parasitas intestinais em 456 crianças de Gombak na Malásia, encontraram $63 \%$ de amostras positivas, o T. trichiura foi o parasita mais comum, contribuindo com $47 \%$ dos casos, seguido por G. lamblia com $15 \%$ e A. lumbricoides $8 \%$. Os pesquisadores encontraram alta prevalência associada com a baixa condiçăo socioeconômica, déficit de 
provisão de água tratada, disposição sanitária de fezes no solo e maior número de componentes familiares.

GBAKIMA e col. em 1994, pesquisando enteroparasitoses em 1820 crianças de cinco escolas primárias e uma escola secundária de Najla, Serra Leoa Sulista observaram o A. lumbricoides como o parasita mais comum, apresentando $33 \%$ de prevalência, seguido pelo $T$. trichiura com $15 \%$.

ENEKWECHI e AZUBIKE, em 1994, numa pesquisa de prevalência de parasitas intestinais desenvolvida com 1536 escolares de Njikoka na Nigéria verificaram $60 \%$ dos resultados positivos, sendo o $A$. lumbricoides o parasita mais comum com $21 \%$ de positividade; seguido pelo $T$. trichiura com $15 \%$, ancilostomideos $13 \%, E$. histolytica $7 \%, T$. saginata $2 \%$, Strongyloides stercoralis $1,3 \%$, Schistosoma mansoni $0,3 \%$ e G. lamblia $0,1 \%$.

BORDA e col. em 1996, num estudo com 207 crianças da localidade de San Cayetano, Argentina desprovida de água tratada, encontraram formas parasitárias em $72 \%$ das amostras. O parasita mais comum foi a G. lamblia (29\%), seguido pela E. coli $(27 \%)$, Enterobius vermicularis $(4 \%), S$. stercoralis(2\%), A. lumbricoides, T. trichiura, T. saginata, Isospora belli, lodamoeba bütschlii, e Balantidium coli $(0,5 \%)$.

PERÉZ e col. (1997), pesquisando a prevalência de enteroparasitoses em escolares do ensino fundamental de uma região saneada do Vale de Guadalquivir, Espanha encontraram $27 \%$ de amostras positivas, sendo o $E$. vermicularis o parasita mais freqüente, contribuindo com $20 \%$ dos casos, 
seguido pela G. lamblia (5.\%), E. coli (2.5\%), Endolimax nana (1.6\%), E. histolytica (0.3\%), Entamoeba hartmanni e I. bütschlii (0.05\%).

TÉLLEZ e col. (1997) num estudo de prevalência de parasitoses intestinais em 1267 individuos da cidade León, Nicarágua, caracterizada por possuir água encanada, encontraram $47 \%$ de positividade geral, a $E$. histolytica contribuiu com $18.6 \%$ dos casos, a G. lamblia com $15.9 \%$ e o A. lumbricoides $13,4 \%$. Dentre os casos positivos $81 \%$ apresentavam deficientes condições socioeconômicas.

KIM e col. (2003) analisando 301 coproparasitológicos de crianças entre 1 e 15 anos de idade, da Localidade de Mindoro na cidade de Roxas, Filipinas encontraram $64 \%$ de positividade geral, o helminto mais comum foi o $A$. lumbricoides com $51 \%$ de prevalência, seguido pelo $T$. trichiura $(28 \%), E$. coli $(15 \%)$ e E. vermicularis $(0.3 \%)$.

GAMBOA e col. em 2003, pesquisando condiçōes socioeconômicas em três comunidades com condiçōes sanitárias distintas de La Plata na Argentina, analisaram 292 amostras fecais de crianças com até 14 anos de idade. A prevalência entre as comunidades variou entre $35 \%$ e $73 \%$, sendo maior a prevalência onde as condições sanitárias e ambientais eram mais deficientes.

HOSAIN e col. (2003) pesquisando escolares em Bangladesh, encontraram $53 \%$ de positividade geral, sendo o $A$. lumbricoides o parasita mais comum com $36 \%$ de prevalência.

AHMED e col. em 2003, pesquisando infecção parasitária em 283 crianças entre 5 e 12 anos de idade de Abbottadad, Paquistão encontraram 
$81 \%$ de casos positivos e dentre estes o $A$. lumbricoides foi o parasita mais freqüente, contribuindo com $48 \%$.

MORALES e col. em 2003, pesquisando parasitismo intestinal em 1478 crianças abaixo de 15 anos de idade em área desprovida de saneamento na região de Borba, localidade de Chiapas no México, encontrou $67 \%$ de positividade, predominando os casos de amebiase $(51,2 \%)$, seguido pela giardiase (18\%) e ascaridiase (15\%).

BALDO e col. (2004) estudando a prevalência de parasitas intestinais em 284 crianças de uma comunidade desprovida de água tratada de Manila nas Filipinas, encontrou $62 \%$ de positividade, sendo que os parasitas mais comuns foram o T. trichiura (45\%) e o A. lumbricoides (36\%).

Os dados anteriores indicam que os parasitas intestinais ainda produzem um elevado número de parasitados, principalmente nas regiōes e países com menor desenvolvimento sanitário, social e econômico. Entretanto, mesmo nos paises desenvolvidos como no vale de Guadalquivir na Espanha, as taxas de enteroparasitoses apresentam-se elevadas.

\subsection{Enteroparasitoses no Brasil}

No Brasil, grandes inquéritos coproparasitológicos foram realizados até a década de 70. Atualmente apenas trabalhos isolados são realizados, o que compromete a comparação dos dados pela diversidade social, econômica e cultural do pais, entretanto MACEDO e col. (1998) estimam que nas regiōes com infra-estrutura urbana deficiente, pelo menos metade das crianças estejam contaminadas por enteroparasitas. 
O Brasil passa por uma transição epidemiológica em relação às doenças infecto-parasitárias. Segundo JORGE e col. (2001) a mortalidade por doenças infecciosas e parasitárias vem declinando continuamente, de 1996 a 1999 o decréscimo foi de aproximadamente $15 \%$, sendo que no Sudeste correspondeu a $22 \%$ e no Nordeste $20 \%$. Segundo o mesmo autor, dentre as mortes provocadas por doenças infecciosas no Brasil, ainda predominam os óbitos por infecções intestinais. De 1996 a 1999, as infecçōes intestinais variaram de uma participação mínima de $16 \%$ e máxima de $18 \%$, sendo que as taxas mais altas dessa patologia prevaleceram no Nordeste. Contudo, este estudo se refere à mortalidade por doenças infecciosas e parasitárias e não somente parasitárias.

A inexistência de notificação das enteroparasitoses e o reduzido número de pesquisas relacionadas ao assunto contribuem para a falta de informação a respeito do impacto que essas doenças causam na população. Alguns trabalhos têm sido realizados no Brasil apresentando diferentes taxas nas mais diversas regiōes. De forma geral as taxas permaneceram elevadas em todas as pesquisas, conforme os resultados que se seguem.

PEREIRA e col. (1987) analisando os resultados de 117.590 exames coproparasitológicos que abrangeu pessoas de diferentes idades e condiçōes socioeconômicas da Grande Vitória-ES, verificaram $61 \%$ dos resultados positivos, o T. trichiura foi o parasito mais freqüente com $28 \%$ dos casos, seguido pelo A. lumbricoides com $21 \%$, ancilostomídeos (16\%), S. stercoralis (15\%), G. lamblia (10\%), S. mansoni (6\%) e E. histolytica (4\%). 
ALMEIDA (1991), usando estudos transversais de prevalência de parasitoses intestinais na população do bairro Nossa Senhora de Fátima-DF, caracterizado pela ausência de água tratada e rede de esgoto, verificou que das 298 crianças entre 1 e 12 anos de idade, 95\% estavam contaminadas por parasitas intestinais, sendo que $81 \%$ das contaminadas estavam poliparasitadas.

ROCHA e col. em 1994, analisando 1.352 exames coproparasitológicos de escolares de 7 a 15 anos de idade de três escolas públicas de Belo Horizonte-MG, verificaram $78 \%$ de prevalência geral, o T. trichiura foi o parasito mais prevalente chegando a $61 \%$ de prevalência, seguido pelo $A$. lumbricoides que contribuiu com $34 \%$ dos casos.

Trabalhando com comunidades que dispōem de, no mínimo, água tratada, FERREIRA e MARÇAL (1997) pesquisando parasitas intestinais em crianças entre 6 e 14 anos de idade em um distrito saneado de Uberlândia-MG encontraram $22,3 \%$ de prevalência geral.

FERNANDES e col. (1998) acompanharam 55 crianças de 0 a 24 meses de idade, pertencentes a um bairro sem saneamento básico, observaram que somente cinco $(9 \%)$ crianças mantiveram-se negativas para o exame parasitológico de fezes até os 24 meses de idade.

CASTRO E MOLINA (1998), num inquérito coproparasitológico realizado em 3.769 pessoas carentes do municipio de Mambai, Góiais encontraram $3.295(87,4 \%)$ de parasitados. A ancilostomose foi a única parasitose com alta prevalência $(76,7 \%)$. O $A$. lumbricoides e o $T$. trichiura apresentaram taxas 
reduzidas. Dentre os protozoários patogênicos a E. histolytica e a G. lamblia apresentaram prevalência de $8,3 \%$ e $3,3 \%$ respectivamente. Salientaram ainda que de 1974 a 1986 a prevalência de ancilostomose na zona urbana oscilou de $66,1 \%$ para $55,8 \%$.

MACHADO e CRUZ em 1998, pesquisando enteroparasitas em 300 escolares de Uberlândia-MG, verificaram que 265 (88,4\%) crianças estavam parasitadas. A G. lamblia contribuiu com $78,3 \%$ e o A. lumbricoides $15,3 \%$ dos casos.

$\mathrm{HACHICH}$, em 2002, avaliou a presença de G. lamblia em águas superficiais destinadas a captação e tratamento para consumo humano no Estado de São Paulo. Verificou que dentre o total de 278 amostras de 5 litros, analisadas em 10 Unidades de Gerenciamento de Recursos Hídricos, $27 \%$ das amostras estavam contaminadas e as concentraçōes obtidas variaram de 0 a 521 cistos/L.

MUNIZ e col. (2002), pesquisaram a prevalência de infecçōes parasitárias intestinais em 1044 crianças com menos de 5 anos de idade na cidade de São Paulo-SP, verificando $11 \%$ de crianças parasitadas, sendo a $G$. lamblia o parasita mais comum com (6\%), seguido pelo $A$. lumbricoides (4\%) e T. trichiura (1\%).

FERREIRA e col. (2003), estudando 72 crianças carentes do ensino fundamental de Campo Florido-MG, verificaram $60 \%$ das crianças parasitadas. 
As taxas de positividade no Brasil são semelhantes às encontradas em outros paises e variam de acordo com as caracteristicas regionais de saneamento e condiçōes socioeconômicas.

\subsection{Enteroparasitoses e Saneamento}

A disponibilidade de água tratada e o destino adequado do esgoto contribuem para a reduçāo das infecçōes intestinais. Indicando algumas relações entre enteroparasitoses e saneamento vale citar os seguintes estudos:

TEODORO e col. (1988), verificaram que dos 1190 exames coproparasitológicos realizados no municipio de Maringá, 678 (56,9\%) mostraram-se positivos, sendo que a taxa de parasitismo entre as pessoas que consumiam água encanada foi de $54 \%$, entre indivíduos que consumiam água de poço foi verificado $72 \%$ de parasitados, nos domicílios que possuíam água encanada e rede de esgoto, a parcela de indivíduos com diagnóstico positivo foi de $44 \%$ e nas residências onde a fossa era meio de descarte de dejetos fecais a taxa de pessoas parasitadas subiu para $62 \%$.

GROSS (1989), afirma que em Belo Horizonte-MG houve redução de 45\% na incidência de diarréia em crianças com idade abaixo de seis anos devido a melhorias no abastecimento de água e $44 \%$ por causa das melhorias na captação de esgoto. Ainda nessa pesquisa o autor cita que não observou impacto significativo na prevalência geral das parasitoses intestinais.

Segundo MARTINS (2001), a redução de doenças infecciosas intestinais e helmintiases atribuida à implantação de sistemas públicos de abastecimento 
de água tratada variou de $65 \%$ a $78 \%$. As helmintiases representaram $77 \%$ dos casos e as demais doenças infecciosas intestinais $23 \%$.

MORAES e col. (2004), estudando parasitoses intestinais em 120 crianças de 5 a 14 anos da periferia de Salvador-BA, observaram que a implantação de sistema de captação e tratamento de esgoto reduziu em $28 \%$ a prevalência de ascaridiase, $19,5 \%$ de trichuriase e $15,8 \%$ de ancilostomídeos.

Os resultados até aqui apresentados indicam que medidas de saneamento contribuem para o controle das parasitoses intestinais, porém em nenhum dos relatos os parasitas foram eficazmente controlados.

\subsection{Enteroparasitoses e Condiçōes Socioeconômicas}

Os parasitas intestinais, exceto o Schistosoma mansoni, possuem formas resistentes que mantêm sua capacidade infectante por longos períodos, tanto na presença como na ausência de umidade. Essa caracteristica associada às diversas maneiras de veiculação das formas infectantes contribui para a persistência de um significativo número de indivíduos contaminados. Portanto, outros fatores além da água tratada e captação de esgoto contribuem para a alta prevalência das enteroparasitoses.

Segundo NEGHEME e SILVA (1971), maus hábitos de higiene e moradias inadequadas, decorrentes do baixo nível sócio-econômico, agravados pela precariedade do saneamento ambiental são fatores que contribuem para a persistência de enteroparasitas em uma comunidade, por isso, o controle das doenças parasitárias intestinais bem como a prevenção de cada uma delas, além das açōes em saneamento, exige conhecimento dos fenômenos 
ecológicos, sociais e culturais que envolvem o homem, pois os parasitos perpetuam seu ciclo biológico não somente em função do veículo hídrico, mas também, dos hábitos e costumes de uma população. Nesse contexto as populaçōes carentes estão mais expostas a infecção.

Indicando relação entre nível sócio-econômico e parasitoses intestinais, KROMBAUER e col. (1997) através de exames parasitológicos de fezes de 166 crianças de 1 a 7 anos de idade que freqüentavam creches da cidade de Porto Alegre-RS, verificaram que do total das crianças pesquisadas, 92 freqüentavam creches da classe econômica média e 74 da classe econômica baixa. Do total das crianças estudadas, 94 (57\%) estavam parasitadas, sendo que na primeira, os autores encontraram $34(37 \%)$ e na segunda 60 (81\%) crianças parasitadas.

MONTEIRO e col. (1988), que em pesquisa coproparasitológica realizada na cidade de São Paulo-SP, caracterizada por dispor de água tratada e captação de esgoto, encontrou prevalência de $31 \%$ de enteroparasitoses em crianças de 0 a 59 meses de idade, lembrando que LOVE, em 1982, referiu que já em 1920, metade dos municípios paulistas possuía sistemas de esgotamento sanitário e que a grande maioria das cidades paulistas já eram atendidas por sistemas de abastecimento de água. Mesmo assim, encontrouse uma prevalência significativa nesta região que é a mais desenvolvida do país. 


\subsection{Enteroparasitoses e Hortaliças}

A fim de prevenir as infecções parasitárias, especial atenção deve ser dada ao consumo de hortaliças, pois alguns autores têm reforçado sua importância como via de transmissāo de enteroparasitoses.

MARZOCHI (1997), afirma que freqüentemente as verduras são adubadas com dejetos humanos e irrigadas com água contaminada. Soma-se a estes fatos o hábito bastante difundido na população de consumir hortaliças cruas, o que expõe um grande número de individuos a essa forma de transmissão.

MESQUITA e col. (1999), pesquisaram 128 amostras (pés de alface) adquiridas em diferentes pontos comerciais das cidades de Niterói e Rio de Janeiro-RJ. Observaram que nenhuma amostra estava contaminada.

GUILHERME e ARAUJO (1999) investigaram a contaminação de hortaliças consumidas cruas vendidas na Feira do Produtor de Maringá. Observaram que $16,6 \%$ das 144 amostras de cinco diferentes tipos de hortaliças estavam contaminadas por enteroparasitas.

TAKAYANAGUI (2000), avaliando as condiçōes higiênico-sanitárias de todas as hortas produtoras de verduras de Ribeirão Preto-SP, verificou $13,1 \%$ de hortaliças contaminadas, dentre estas: ancilostomideos contribuíram com $8,5 \%$, Entamoeba sp com 7,7\%, Hymenolepis nana com 1,5\%, Giardia sp com $0,7 \%$, Strongyloides sp com $0,7 \%$ e Ascanis sp com $0,7 \%$. 
COELHO e col. (2001), pesquisando a presença de formas transmissiveis de enteroparasitas em hortaliças consumidas cruas, encontraram 3,9\% de contaminação pelos espécimes Hymenolepis diminuta, $S$. stercoralis e ancilostomideos. As hortaliças lavadas continham S. stercoralis, ancilostomídeos, $A$. lumbricoides e G. lamblia totalizando $1,3 \%$, demonstrando que a lavagem não garantiu a ausência de contaminação nas hortaliças.

KOSAN e col. em 2004, estudando a prevalência de ovos de helmintos em 203 amostras não lavadas e 406 amostras lavadas de vegetais normalmente consumidos crus na cidade de Ankara na Turquia, observaram que somente as hortaliças não lavadas estavam contaminadas, totalizando 12 $(5,9 \%)$ amostras positivas. O ovo de Taenia sp foi a forma evolutiva mais freqüente $(3,5 \%)$, contaminando cebolas verdes, pepinos, cenouras e principalmente a salsa que foi a hortaliça mais contaminada, entretanto não foi encontrado em nenhuma amostra de alface. O ovo de Ascaris sp foi encontrado somente na alface contribuindo com $1 \%$ da prevalência.

Os resultados anteriormente citados indicam que as hortaliças tenderam a apresentar-se contaminadas, sendo que entre os estudos a prevalência geral variou entre 0 e $16,6 \%$.

\subsection{População Estudada}

O bairro Santo André na periferia da cidade de Vitória-ES foi eleito para a pesquisa, pois possui características como: rápido crescimento demográfico sobre área de mangue e a cata do lixo como atividade econômica iniciada no final dos anos 70 . O quadro de miséria na região era tão significativo na década 
de 80 , que atraiu a atenção do Papa João Paulo II que realizou um evento religioso na comunidade durante a sua última visita ao Brasil. O documentário em VHS de ALMEIDA (1983), intitulado Lugar de Toda Pobreza, mostra a condição de miséria que existia naquela época. A figura 1 ilustra o procedimento da cata do lixo em 1984.

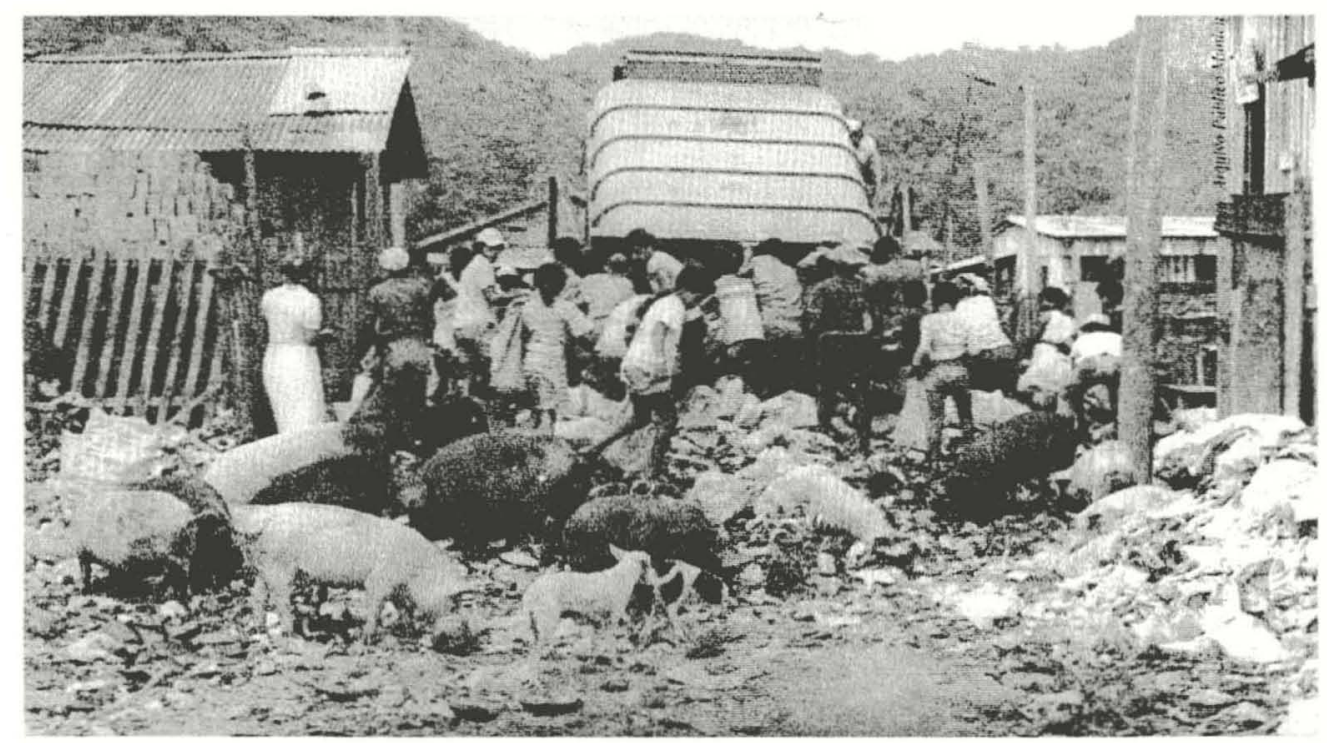

Figura 1 - Cata do lixo no bairro Santo André, Vitória-ES, (1984).

Hoje o bairro dispõe de água tratada, captação de esgoto, coleta de lixo, unidade de saúde e todas as ruas pavimentadas, contudo persiste a condição de baixa classe econômica. A figura 2 mostra uma rua do bairro em 2003 sob o mesmo ângulo focal da figura 1 que foi realizada em 1984. 


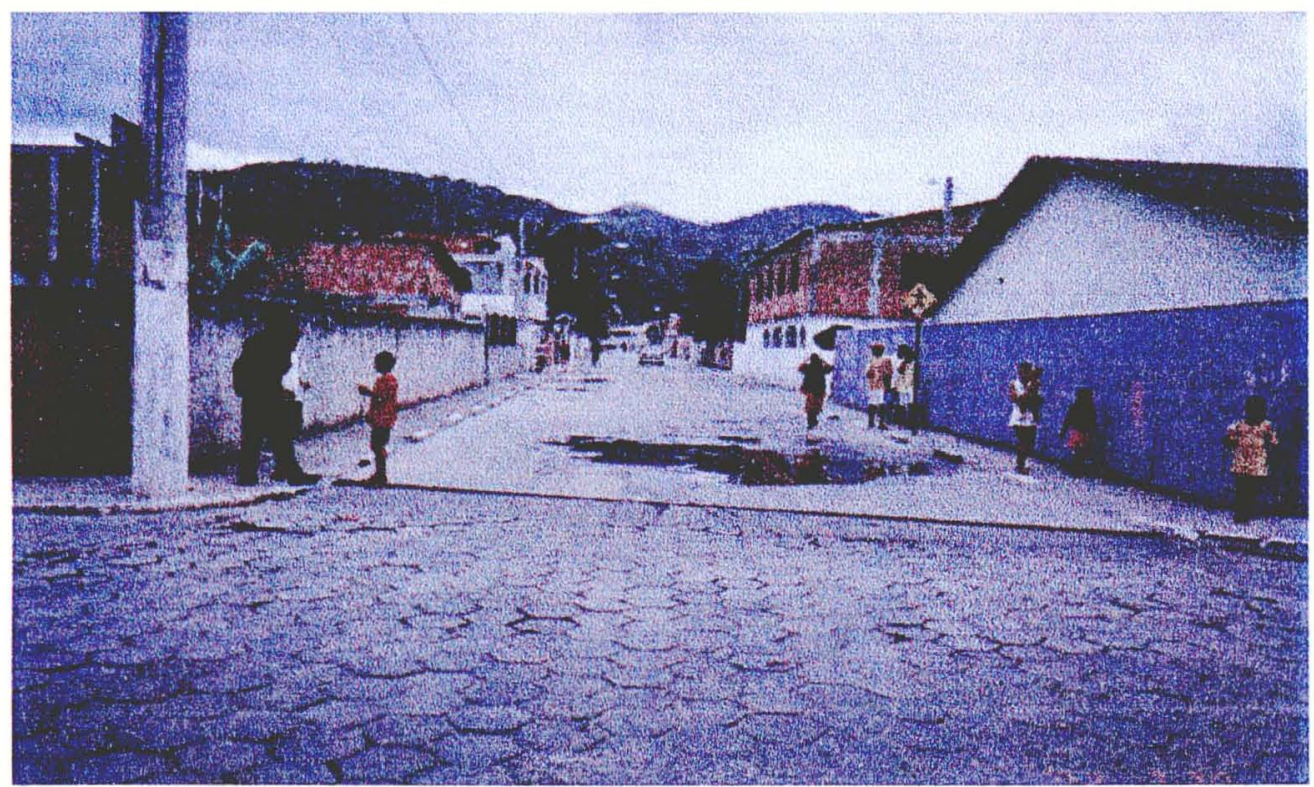

Figura 2 - Rua do bairro Santo André, Vitória-ES (2004).

\subsubsection{Localização}

A Região que compreende o bairro estudado está localizada próxima ao nível do mar, no lado norte-noroeste da ilha de Vitória-ES. É margeada em toda a sua extensão pela rodovia Serafim Derenzi, fica distante cerca de $4 \mathrm{~km}$ do Centro de Vitória, limita-se ao norte com a região da Grande Maruípe, ao sul com a Região de Santo Antônio, a leste com o Maciço Central e ao oeste com o estuário da baía de Vitória (FRANÇA e col. 1995). As figuras 3 e 4 mostram a localização do bairro Santo André. 




ÁREAS ACRESCIDAS DE MARINHA ATERRADAS COM RESIDUOS SOLLIDOS

Figura 3 - Mapa da região da grande vitória com indicação da localização do bairro Santo André.



foto: Prof André Alves

Figura 4 - Vista aérea do bairro Santo André, Vitória-ES, indicado entre as faixas escuras, no centro, (2003). 


\subsubsection{Ocupação do Espaço Físico}

Em 1977, ocorreram as primeiras ocupações por aproximadamente 40 famílias, a maioria migrantes do interior do Espírito Santo, Sul da Bahia, Leste de Minas Gerais e Norte do Rio de Janeiro. Atribui-se essa migração aos grandes projetos industriais implantados na região metropolitana de Vitória durante a década de 70 (FRANÇA e col. 1995).

A maior parte da área foi ocupada por palafitas, construídas sobre o manguezal. Em vários locais foram realizados aterros com lixo urbano sistematicamente depositado pela Prefeitura Municipal de Vitória - e, posteriormente, com terra (NUNES, 1998). A figura 5 ilustra como se dava a ocupação do bairro de Santo André em 1985.

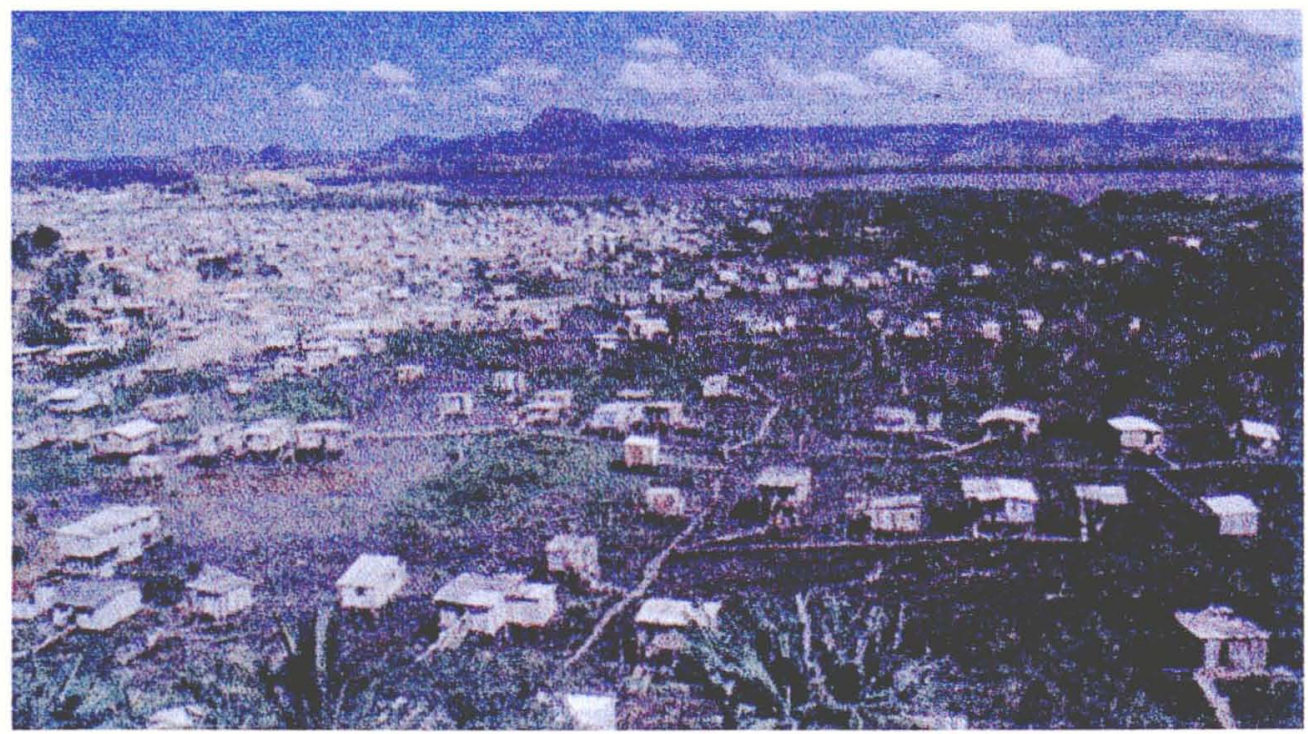

Figura 5 - Ocupação do espaço nas proximidades do bairro Santo André, Vitória-ES, (1984). 
Esse ciclo só seria interrompido no final dos anos 80 e início dos anos 90, com a implantação da usina de lixo de Vitória e desenvolvimento de projetos urbanos e ambientais (LIMA, 2002). A fotografia exposta a seguir mostra o complexo da usina de compostagem e seleção de resíduos urbanos.

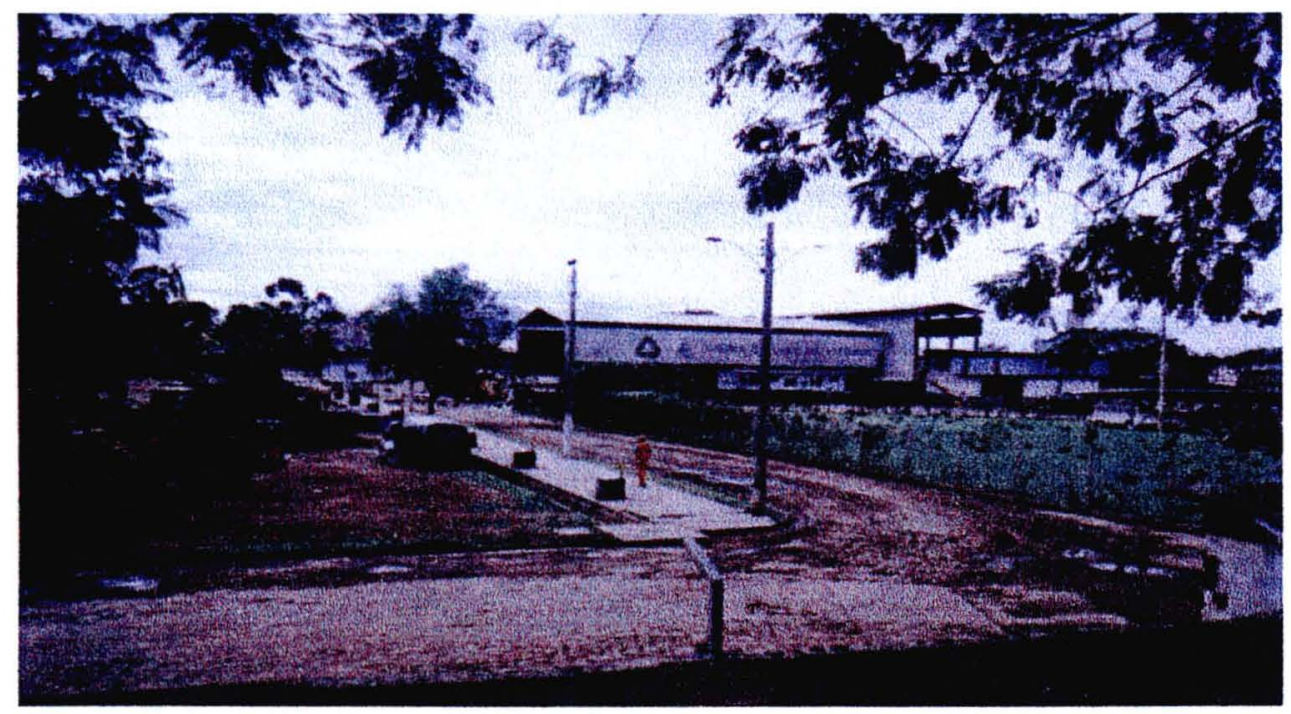

Figura 6 - Usina de lixo localizado nas proximidades do bairro Santo André, Vitória-ES em 2003.

\subsubsection{Características Geográficas}

Atualmente o bairro Santo André faz parte da Região da Grande São Pedro que é composta pelos seguintes bairros: Resistência, Nova Palestina, São Pedro I, II, III e IV, Santo André, Redenção, Condusa e Ilha das Caieiras. A Grande São Pedro abrange uma área com cerca de $1.640 .400 \mathrm{~m} 2$, constituída por relevo montanhoso, planície, regiöes rochosas e vastas áreas de manguezal em toda a extensão dos bairros de Resistência, Nova Palestina, Redenção e Santo André (FRANÇA e col. 1995). 


\subsubsection{Fonte de Renda}

A fonte de renda na região até 1992 era proveniente principalmente das atividades de comércio, prestação de serviço, serviços públicos e atividades da economia informal (pesca, construção civil, comércio ambulante entre outras) (FRANÇA e col. 1995). NUNES, em 1998, salientou a importância da cata do caranguejo como importante fonte de renda na região.

\subsubsection{Caracteristicas Sociais e Sanitárias}

Segundo o SIAB (Sistema de Informação da Atenção Básica) o bairro Santo André pertence à micro regiāo que compreende três bairros, Santo André, Redenção e Condusa que juntos detêm 2358 arranjos familiares, que dentre outras características, apresentam condições adequadas de oferta de água tratada, captação de esgoto e coleta de lixo. Segundo o SIAB - Sistema de Informação da Atenção Básica, o bairro Santo André possui abastecimento com água tratada em $99,9 \%$ das casas, captação de esgoto em $99,1 \%$, coleta bissemanal do lixo em $98,5 \%$. O bairro ainda conta com $87,8 \%$ das casas construídas com alvenaria.

A comunidade conta com uma unidade de saúde que segundo a coordenação local oferece os seguintes programas e serviços relacionados à criança: PAISC - Programa de Atençäo Integral a Saúde da Criança, SISVAN Sistema de Vigilância Alimentar e Nutricional e Combate às Carências Nutricionais, PSE - Programa de Saúde do Escolar, Programa de Atenção à Saúde do Adolescente, Consultas Pediátricas. 


\section{OBJETIVOS}

\subsection{Objetivo geral}

Pesquisar a prevalência e alguns fatores de risco para enteroparasitoses em crianças de 1 a 4 anos de idade do bairro Santo André, Vitória-ES.

\subsection{Objetivos especificos}

$\checkmark$ Pesquisar a prevalência de indivíduos contaminados por parasitas intestinais na faixa etária de 1 a 4 anos de idade;

$\checkmark$ Pesquisar a prevalência de parasitas intestinais em folhosos comercializados na região;

$\checkmark$ Estudar a relação entre características sócio-culturais e contaminação por parasitas intestinais. 


\section{METODOLOGIA}

\subsection{Parcerias}

Para a realização do projeto foi pactuada uma parceria com a Secretaria Municipal de Saúde de Vitória, que através da unidade de saúde local viabilizou consultas pediátricas e tratamento para todos os casos positivos. Houve a colaboração das equipes que atuam no Programa Saúde da Familia, que cederam as informaçōes necessárias e convidaram os positivos para consulta agendada.

Para o primeiro contato com a comunidade e a realização dos exames coproparasitológicos foi desenvolvido um projeto de pesquisa-ação acolhido pela Faculdade de Ciências da Saúde e Ambientais (FAESA) que viabilizou toda estrutura necessária como laboratórios, auditório, recursos humanos e materiais.

\subsection{Entrevista e Coleta}

Antes do trabalho de campo, foi realizado seminário com a comunidade para a divulgação da pesquisa e promoção da educação em saúde voltada para o controle das parasitoses intestinais. O evento contou com a participação de membros da comunidade, agentes de saúde e estudantes da área de saúde e ambiental.

A pesquisa de campo contou com a colaboração de 30 monitores previamente treinados, alunos dos cursos de graduação de Ciências Biológicas

e Enfermagem da FAESA, que após colherem a assinatura do termo de 
consentimento (Anexo 1) realizaram entrevista (Anexo 2) com os pais e responsáveis pelas crianças diretamente em seus domicilios, totalizando 130 entrevistas realizadas, entretanto somente 100 familias coletaram o material fecal, sendo desconsiderados todos os dados da criança e da familia cujo material não foi coletado. A visita domiciliar alcançou aproximadamente $\mathbf{8 0 \%}$ das familias com crianças na faixa etária de 1 a 4 anos de idade pertencentes ao bairro Santo André. Após a realização da entrevista os responsáveis receberam potes coletores e foram orientados para a coleta do material. No dia seguinte a entrevista as amostras foram recolhidas no próprios domicilios e encaminhadas para os laboratórios da FAESA onde foram examinadas.

Segundo GIL (1999), a entrevista é uma técnica muito eficiente para obtenção de dados fidedignos acerca do comportamento humano tornando-os passiveis de classificação e de quantificação.

\subsection{Exame Coproparasitológico}

Os métodos de diagnóstico eleitos para a análise fecal foram os Métodos de Hoffmann/Lutz e Tamisação. O primeiro consiste na sedimentação espontânea do filtrado fecal em um cálice cônico, o concentrado do material é levado ao microscópio óptico onde as formas parasitárias sāo procuradas, sendo que o espécime Enterobius vermicularis não foi sistematicamente analisado, por seus ovos ficarem aderidos ao tegumento do orifício anal. 0 segundo método consiste no peneiramento e lavagem do material fecal para a procura de proglotes de Taenia sp. Esses métodos mostram-se eficazes no diagnóstico dos parasitos intestinais e são utilizados em larga escala pelos 
laboratórios de análises clínicas. Os parasitos pesquisados foram: $A$. lumbricoides, ancilostomídeos, S. stercoralis, T. trichiura, Taenia sp, $H$. nana, E. histolytica e G. lamblia (MONTEIRO 1988). Foi coletada uma amostra fecal de cada criança e confeccionada três lâminas para análise direta.

\subsection{Exame Parasitológico em Hortaliças}

Para a análise da contaminação das hortaliças comercializadas na feira livre e supermercado da localidade, elegeu-se a alface Lactuca sativa nas formas lisa e crespa, pois estas apresentam elevado consumo entre a população, disponibilidade durante praticamente todos os meses do ano e geralmente são ingeridas sem nenhuma cocção prévia. Será considerada, como unidade amostral, o pé (ou touceira) independentemente do peso ou tamanho. As touceiras foram selecionadas de forma aleatória dentre as bancas da feira do bairro e no supermercado local, em número de dez amostras por dia de feira e durante o período de dois meses, totalizando 60 amostras independentemente das formas lisa ou crespa.

A análise parasitológica dos folhosos foi realizada a partir de uma solução contendo $300 \mathrm{ml}$ de detergente neutro em 2 litros de solução fisiológica. Após o desfolhamento cada folha foi esfregada por no mínimo 30 segundos com pincel chato número 16 num recipiente inoxidável, lavado com água destilada e detergente comercial neutro, desinfetado com álcool a $70 \%$ e seco com papel toalha. Cada touceira teve recipiente individual e o produto das lavagens foi deixado em repouso em cálice cônico por 24 horas após filtragem em gaze de 12 dobras. Os helmintos foram diagnosticados através da análise 
direta do sedimento e os protozoários após centrifugo-flutuação em sulfato de zinco (OLIVEIRA, 1991). 


\section{RESULTADOS}

Dentre 100 crianças de 1 a 4 anos pesquisadas, 40 apresentaram alguma forma parasitária intestinal, ou seja, observou-se uma expressiva parcela de contaminados, assim como pode ser visualizado na Figura 7.



Figura 7 - Casos positivos e negativos segundo o exame coproparasitológico de 100 crianças do bairro Santo André, Vitória-ES, 2004.

A Tabela 1 contém a freqüência dos espécimes parasitários encontrados considerando os indivíduos poliparasitados. Verificou-se a presença de 8 diferentes espécimes patogênicos nas crianças da comunidade. 
Tabela 1 - Parasitas encontrados segundo 0 exame coproparasitológico de 100 crianças do bairro Santo André, Vitória-ES, 2004.

\begin{tabular}{lcc}
\hline Espécime parasitário & Número & $\%$ \\
\hline Giardia duodenalis & 24 & 45,3 \\
Ascaris lumbricoides & 15 & 28,3 \\
Trichuris trichiura & 5 & 9,5 \\
Entamoeba histolytica & 3 & 5,6 \\
Strongyloides & 3 & 5,6 \\
stercoralis & & 1,9 \\
Ancylostoma spp & 1 & 1,9 \\
Enterobius vermicularis & 1 & 1,9 \\
Hymenolepis nana & 1 & 100 \\
\hline \multicolumn{1}{c}{ TOTAL } & 53 & \\
\hline
\end{tabular}

Assim como observado na maioria das pesquisas descritas no desenvolvimento deste trabalho, os espécimes Giardia duodenalis e Ascaris lumbricoides também foram os parasitas mais prevalentes.

A G. duodenalis foi o parasita mais freqüente e apresentou número crescente de infectados à medida que a faixa etária aumentava, o mesmo aconteceu com o S. stercoralis e com o T. trichiura. A E. histolytica contribuiu com três casos distribuídos nas extremidades das faixas etárias. Os parasitas $H$. nana, Ancylostoma spp e E. vermicularis contribuiram com apenas um caso 
cada e estes foram observados na faixa etária de maior idade assim como observado na Tabela 2.

Tabela 2 - Espécime parasitário e idade em anos segundo o exame coproparasitológico de 100 crianças do bairro Santo André, Vitória-ES, 2004.

\begin{tabular}{|c|c|c|c|c|c|c|c|c|c|c|}
\hline \multirow[b]{2}{*}{ Espécimes } & \multicolumn{2}{|c|}{1 ano } & \multicolumn{2}{|c|}{2 anos } & \multicolumn{2}{|c|}{3 anos } & \multicolumn{2}{|c|}{4 anos } & \multicolumn{2}{|c|}{ TOTAL } \\
\hline & $\mathbf{n}$ & $\%$ & $\mathbf{n}$ & $\%$ & $n$ & $\%$ & $\mathbf{n}$ & $\%$ & $n$ & $\%$ \\
\hline $\begin{array}{l}\text { Giardia } \\
\text { duodenalis }\end{array}$ & 2 & 3,8 & 5 & 9,4 & 6 & 11,3 & 11 & 20,7 & 24 & 45,2 \\
\hline $\begin{array}{l}\text { Ascaris } \\
\text { lumbricoides }\end{array}$ & 3 & 5,7 & 3 & 5,7 & 2 & 3,8 & 7 & 13,2 & 15 & 28,3 \\
\hline $\begin{array}{l}\text { Trichuris } \\
\text { trichiura }\end{array}$ & 0 & 0 & 0 & 0 & 1 & 1,9 & 4 & 7,5 & 5 & 9,4 \\
\hline $\begin{array}{l}\text { Entamoeba } \\
\text { histolytica }\end{array}$ & 1 & 1,9 & 0 & 0 & 0 & 0 & 2 & 3,8 & 3 & 5,7 \\
\hline $\begin{array}{l}\text { Strongyloides } \\
\text { stercoralis }\end{array}$ & 0 & 0 & 0 & 0 & 1 & 1,9 & 2 & 3,8 & 3 & 5,7 \\
\hline $\begin{array}{l}\text { Enterobius } \\
\text { vermicularis }\end{array}$ & 0 & 0 & 0 & 0 & 0 & 0 & 1 & 1,9 & 1 & 1,9 \\
\hline $\begin{array}{l}\text { Himenolepis } \\
\text { nana }\end{array}$ & 0 & 0 & 0 & 0 & 0 & 0 & 1 & 1,9 & 1 & 1,9 \\
\hline $\begin{array}{l}\text { Ancylostoma } \\
\text { spp }\end{array}$ & 0 & 0 & 0 & 0 & 0 & 0 & 1 & 1,9 & 1 & 1,9 \\
\hline TOTAL & 6 & 11,4 & 8 & 15,1 & 10 & 18,9 & 29 & 55,7 & 53 & 100 \\
\hline
\end{tabular}

A maior prevalência de poliparasitados manteve-se na faixa etária de maior idade, com $71,4 \%$ dos casos (Tabela 3 ). 
Tabela 3 - Poliparasitados e idade em anos segundo 0 exame coproparasitológico de 100 crianças do bairro Santo André, Vitória-ES, 2004.

\begin{tabular}{lcccccccccc}
\hline Idade & $\mathbf{1}$ ano & \multicolumn{2}{c}{$\mathbf{2}$ anos } & \multicolumn{2}{c}{3 anos } & \multicolumn{2}{c}{4 anos } & \multicolumn{2}{c}{ TOTAL } \\
\hline Poliparasitismo & $\mathbf{n}$ & $\%$ & $\mathbf{n}$ & $\%$ & $\mathbf{n}$ & $\%$ & $\mathbf{n}$ & $\%$ & $\mathbf{n}$ & $\%$ \\
\hline Biparasitado & 0 & 0 & 1 & 14,3 & 0 & 0 & 2 & 28,6 & 3 & 42,8 \\
Triparasitado & 0 & 0 & 0 & 0 & 1 & 14,3 & 1 & 14,3 & 2 & 28,6 \\
Tetraparasitado & 0 & 0 & 0 & 0 & 0 & 0 & 2 & 28,6 & 2 & 28,6 \\
\hline \multicolumn{1}{c}{ TOTAL } & $\mathbf{0}$ & $\mathbf{0 , 0}$ & $\mathbf{1}$ & $\mathbf{1 4 , 3}$ & $\mathbf{1}$ & $\mathbf{1 4 , 3}$ & $\mathbf{5}$ & $\mathbf{7 1 , 5}$ & $\mathbf{7}$ & $\mathbf{1 0 0}$ \\
\hline
\end{tabular}

A fim de verificar possiveis associaçōes entre diversas variáveis e o resultado dos exames parasitológicos, realizou-se o teste Qui-Quadrado adotando $5 \%$ como nivel de significância. Quando verificada associação das variáveis com o resultado geral, estudou-se: sexo, idade, última consulta médica, exame parasitológico de fezes, último tratamento, tipo de tratamento, defecação no solo, freqüência à creche, hábito de comer alface, forma de lavar alface, tipo de moradia, presença de banheiro, disponibilidade de filtro e tipo de esgoto. As Figuras de 9 a 17 do anexo expõem de forma mais clara os dados mais relevantes.

A Tabela 4 mostra a associação do resultado positivo do exame coproparasitológico com a idade, último tratamento, defecação no solo, freqüentar creches, disponibilidade de filtro e forma de lavar alface. 
Tabela 4 - Prevalência, porcentagem e significância de variáveis diversas segundo exame coproparasitológico de 100 crianças do bairro Santo André, Vitória-ES, 2004.

\begin{tabular}{|c|c|c|c|c|c|c|c|c|}
\hline & & \multicolumn{2}{|c|}{ Positivo } & \multicolumn{2}{|c|}{ Nerivivo } & \multicolumn{3}{|c|}{ Teate Qui-Qundrado } \\
\hline & & $\mathbf{N}$ & $\%$ & $\mathbf{N}$ & $\%$ & Valor & $q$ & p-valor \\
\hline Sexo & $\begin{array}{l}\text { Masculino } \\
\text { Feminino }\end{array}$ & $\begin{array}{l}22 \\
18 \\
\end{array}$ & $\begin{array}{l}41,51 \\
38,30 \\
\end{array}$ & $\begin{array}{l}31 \\
29 \\
\end{array}$ & $\begin{array}{l}58,49 \\
61,70 \\
\end{array}$ & 0,11 & 1 & 0,7435 \\
\hline Idede & $\begin{array}{l}\text { ano } \\
2 \text { anos } \\
3 \text { anos } \\
4 \text { anos } \\
\end{array}$ & $\begin{array}{c}5 \\
8 \\
8 \\
19 \\
\end{array}$ & $\begin{array}{l}18,52 \\
40,00 \\
33,33 \\
65,52 \\
\end{array}$ & $\begin{array}{l}22 \\
12 \\
16 \\
10 \\
\end{array}$ & $\begin{array}{l}81,48 \\
60,00 \\
66,67 \\
34,48 \\
\end{array}$ & 13,50 & 3 & 0,0037 \\
\hline $\begin{array}{l}\text { Uitim } \\
\text { consulth } \\
\text { (em mesee) }\end{array}$ & $\begin{array}{l}0 \mid-3 \\
3 \mid-6 \\
6 \mid-12 \\
12 \mid-24 \\
24 \text { ou mais }\end{array}$ & $\begin{array}{c}21 \\
8 \\
4 \\
3 \\
4\end{array}$ & $\begin{array}{l}34,43 \\
53,33 \\
30,77 \\
50,00 \\
80,00 \\
\end{array}$ & $\begin{array}{c}40 \\
7 \\
9 \\
3 \\
1\end{array}$ & $\begin{array}{l}65,57 \\
46,67 \\
69,23 \\
50,00 \\
20,00 \\
\end{array}$ & 5,96 & 4 & 0,2023 \\
\hline $\begin{array}{c}\text { Fez eximm } \\
\text { de tezes }\end{array}$ & Sim & $\begin{array}{l}27 \\
13\end{array}$ & $\begin{array}{l}40,91 \\
38,24\end{array}$ & $\begin{array}{l}39 \\
21\end{array}$ & $\begin{array}{l}59,09 \\
61,76 \\
\end{array}$ & 0,07 & 1 & 0,7860 \\
\hline $\begin{array}{l}\text { Únimo } \\
\text { exeme } \\
\text { (em meses) }\end{array}$ & $\begin{array}{l}0 \mid-3 \\
31-6 \\
6 \mid-12 \\
12 \mid-24 \\
24 \text { ou mais } \\
\text { Nunca } \\
\text { Nao Sabe }\end{array}$ & $\begin{array}{c}8 \\
2 \\
4 \\
10 \\
1 \\
13 \\
2 \\
\end{array}$ & $\begin{array}{c}47,06 \\
33,33 \\
28,57 \\
38,46 \\
100,00 \\
39,39 \\
66,67 \\
\end{array}$ & $\begin{array}{c}9 \\
4 \\
10 \\
16 \\
- \\
20 \\
1\end{array}$ & $\begin{array}{c}52,94 \\
66,67 \\
71,43 \\
61,54 \\
0,00 \\
60,61 \\
33,33 \\
\end{array}$ & 3,09 & 5 & 0,6858 \\
\hline $\begin{array}{l}\text { Úlimo } \\
\text { tratamento } \\
\text { (em meses) }\end{array}$ & $\begin{array}{l}0 \mid-3 \\
3 \mid-6 \\
6 \mid-12 \\
13 \mid-24 \\
\text { Nunca } \\
\text { Nao Sabe }\end{array}$ & $\begin{array}{c}6 \\
7 \\
6 \\
6 \\
11 \\
4\end{array}$ & $\begin{array}{l}40,00 \\
87,50 \\
33,33 \\
40,00 \\
28,21 \\
80,00 \\
\end{array}$ & $\begin{array}{c}9 \\
1 \\
12 \\
9 \\
28 \\
1\end{array}$ & $\begin{array}{l}60,00 \\
12,50 \\
66,67 \\
60,00 \\
71,79 \\
20,00 \\
\end{array}$ & 10,35 & 4 & 0,0340 \\
\hline Tipo de & $\begin{array}{l}\text { Automedicaçato } \\
\text { Receita medica } \\
\text { Nunca }\end{array}$ & $\begin{array}{l}10 \\
17 \\
13 \\
\end{array}$ & $\begin{array}{l}55,56 \\
40,48 \\
32,50 \\
\end{array}$ & $\begin{array}{c}8 \\
25 \\
27 \\
\end{array}$ & $\begin{array}{l}44,44 \\
59,52 \\
67,50 \\
\end{array}$ & 2,76 & 2 & 0,2520 \\
\hline $\begin{array}{l}\text { Local de } \\
\text { defecaçlo }\end{array}$ & $\begin{array}{l}\text { Banheiro } \\
\text { Solo } \\
\text { Outros }\end{array}$ & $\begin{array}{c}20 \\
18 \\
2 \\
\end{array}$ & $\begin{array}{l}33,90 \\
62,07 \\
16,67 \\
\end{array}$ & $\begin{array}{l}39 \\
11 \\
10 \\
\end{array}$ & $\begin{array}{l}66,10 \\
37,93 \\
83,33 \\
\end{array}$ & 9,73 & 2 & 0,0077 \\
\hline $\begin{array}{c}\text { Frequents } \\
\text { creche }\end{array}$ & Sim & $\begin{array}{l}33 \\
7\end{array}$ & $\begin{array}{l}48,53 \\
21,88 \\
\end{array}$ & $\begin{array}{l}35 \\
25 \\
\end{array}$ & $\begin{array}{l}51,47 \\
78,13 \\
\end{array}$ & 6.44 & 1 & 0.0111 \\
\hline $\begin{array}{l}\text { Comb } \\
\text { alfece }\end{array}$ & Sim & $\begin{array}{c}32 \\
8\end{array}$ & $\begin{array}{l}44,44 \\
28,57\end{array}$ & $\begin{array}{l}40 \\
20\end{array}$ & $\begin{array}{l}55,56 \\
71,43 \\
\end{array}$ & 2,12 & 1 & 0,1457 \\
\hline $\begin{array}{l}\text { Como lava } \\
\text { o slface }\end{array}$ & $\begin{array}{l}\text { Folha/Folha } \\
\text { Outros }\end{array}$ & $\begin{array}{c}35 \\
5\end{array}$ & $\begin{array}{c}36,84 \\
100,00\end{array}$ & $\begin{array}{c}60 \\
- \\
\end{array}$ & $\begin{array}{l}63,16 \\
0,00\end{array}$ & 9,56 & 1 & 0,0020 \\
\hline $\begin{array}{l}\text { Tipo de } \\
\text { moradia }\end{array}$ & $\begin{array}{l}\text { Alvenaria } \\
\text { Madeira }\end{array}$ & $\begin{array}{c}37 \\
3\end{array}$ & $\begin{array}{l}39,78 \\
42,86\end{array}$ & $\begin{array}{c}56 \\
4\end{array}$ & $\begin{array}{l}60,22 \\
57,14\end{array}$ & 0,03 & 1 & 0,8733 \\
\hline $\begin{array}{l}\text { Presenca } \\
\text { de banheiro }\end{array}$ & $\begin{array}{l}\text { Sim } \\
\text { Năo }\end{array}$ & $\begin{array}{l}40 \\
-\end{array}$ & $\begin{array}{l}41.24 \\
0,00\end{array}$ & $\begin{array}{c}57 \\
3\end{array}$ & $\begin{array}{c}58,76 \\
100,00\end{array}$ & 3,13 & 1 & 0,0770 \\
\hline $\begin{array}{l}\text { Presença } \\
\text { de filturo }\end{array}$ & $\begin{array}{l}\text { Sim } \\
\text { Naso }\end{array}$ & $\begin{array}{l}22 \\
18 \\
\end{array}$ & $\begin{array}{l}31,43 \\
60,00 \\
\end{array}$ & $\begin{array}{l}48 \\
12 \\
\end{array}$ & $\begin{array}{l}68,57 \\
40,00 \\
\end{array}$ & 7.14 & 1 & 0,0078 \\
\hline $\begin{array}{l}\text { Tipo de } \\
\text { eagoto }\end{array}$ & $\begin{array}{l}\text { Captado } \\
\text { Fossa }\end{array}$ & $\begin{array}{c}39 \\
1 \\
\end{array}$ & $\begin{array}{l}41,94 \\
14,29 \\
\end{array}$ & $\begin{array}{l}54 \\
6 \\
\end{array}$ & $\begin{array}{l}58,06 \\
85,71 \\
\end{array}$ & 2,37 & 1 & 0,1241 \\
\hline
\end{tabular}


O sexo mais acometido foi o masculino, que contribuiu com $22 \%$ dos casos positivos, porém as parasitoses intestinais tendem a acometer igualmente meninos e meninas.

A idade mais acometida foi a de 4 anos. Verificou-se relação estatística entre maior idade e prevalência por parasitoses intestinais, verificando-se significância de $p=0,0037$.

Foi observado que $61 \%$ das crianças estudadas haviam sido submetidas à consulta médica a pelo menos 3 meses e que dessas, $21 \%$ ainda continuavam parasitadas.

Observou-se que $34 \%$ das crianças estudadas nunca foram submetidas ao exame coproparasitológico. Dentre as crianças submetidas a esse exame, $23 \%$ tiveram seu material fecal analisado a pelo menos 6 meses. Uma observação interessante foi que também $23 \%$ das crianças foram submetidas a tratamento antiparasitário a pelo menos 6 meses.

Analisando os dados da forma de medicação, foi observado que $18 \%$ das crianças foram submetidas a automedicação, $42 \%$ foram medicadas através de receita médica e $40 \%$ nunca foi submetida a nenhuma forma de tratamento.

Outro dado interessante foi que $29 \%$ das crianças defecavam regularmente no solo, apesar de $100 \%$ delas disporem de banheiro com vaso sanitário em suas residências. 
A maioria (68\%) das crianças estudadas freqüenta creche regularmente. Foi estabelecida relação estatística $(p=0,0111)$ entre freqüência a creche e parasitoses intestinais. Não foi possivel estabelecer nenhuma relação da freqüência à creche com nenhum parasito especifico, porém a G. duodenalis foi o espécime mais comum dentre as crianças freqüentadoras desse ambiente.

Com relação ao hábito alimentar, $72 \%$ das crianças consumia alface regularmente, dentre essas, apenas $5 \%$ dos responsáveis relataram não lavar o vegetal folha por folha, dessas, todas estavam parasitadas, estabelecendo relação estatistica $(p=0,002)$ entre não lavar a hortaliça folha por folha e parasitoses intestinais.

Com relação às moradias, $93 \%$ eram construídas com material de alvenaria, $97 \%$ dispunham de banheiro e $93 \%$ tinham o esgoto captado.

Foi observado que $30 \%$ das crianças não dispunham de filtro nos seus domicilios e que $18 \%$ dentre essas estavam parasitadas, estabelecendo relação estatística $(p=0,0075)$ entre nāo a disponibilidade de filtro no domicilio e parasitoses intestinais.

Uma vez que a $G$. duodenalis e o $A$. lumbricoides apresentaram maior prevalência, foi realizado o teste Qui-quadrado para esses parasitas e algumas variáveis conforme Tabelas 5 e 6.

$\mathrm{Na}$ análise de determinados fatores de risco para as espécies estudadas não foi encontrado nenhum caso de associação positiva para nenhuma das variáveis estudadas, assim como mostram as tabelas. 
Tabela 5 - Número e proporçăo de variáveis qualitativas entre grupos de crianças com ausência e presença de $G$. duodenalis, segundo exame coproparasitológico de 100 crianças do bairro Santo André, Vitória-ES, 2004.

\begin{tabular}{|c|c|c|c|c|c|c|c|c|}
\hline & & \multicolumn{2}{|c|}{ Positivo } & \multicolumn{2}{|c|}{ Negativo } & \multicolumn{3}{|c|}{ Teste Qui-Quadrado } \\
\hline & & $\mathbf{N}$ & $\%$ & $\mathbf{N}$ & $\%$ & Valor & $\mathrm{gl}$ & p-valor \\
\hline $\begin{array}{c}\text { Presença } \\
\text { de filtro }\end{array}$ & $\begin{array}{l}\text { sim } \\
\text { não }\end{array}$ & $\begin{array}{c}15 \\
9\end{array}$ & $\begin{array}{l}21,4 \\
30.0\end{array}$ & $\begin{array}{l}55 \\
21\end{array}$ & $\begin{array}{c}78,6 \\
70\end{array}$ & 0,85 & 1 & 0,3577 \\
\hline $\begin{array}{l}\text { Frequenta } \\
\text { creche }\end{array}$ & $\begin{array}{l}\text { sim } \\
\text { não }\end{array}$ & $\begin{array}{c}20 \\
4\end{array}$ & $\begin{array}{r}29,4 \\
12,5\end{array}$ & $\begin{array}{l}48 \\
28\end{array}$ & $\begin{array}{l}70,6 \\
87,5\end{array}$ & 3,41 & 1 & 0,0647 \\
\hline $\begin{array}{l}\text { Tipo de } \\
\text { tratamento }\end{array}$ & $\begin{array}{l}\text { automedicaçāo } \\
\text { receita médica } \\
\text { nunca }\end{array}$ & $\begin{array}{l}5 \\
12 \\
7\end{array}$ & $\begin{array}{l}27,8 \\
28,6 \\
17,5\end{array}$ & $\begin{array}{l}13 \\
30 \\
33\end{array}$ & $\begin{array}{l}72,2 \\
71,4 \\
82,5\end{array}$ & 1,59 & 2 & 0,4509 \\
\hline $\begin{array}{l}\text { Come } \\
\text { alface }\end{array}$ & $\begin{array}{l}\text { sim } \\
\text { não }\end{array}$ & $\begin{array}{c}18 \\
6\end{array}$ & $\begin{array}{c}25 \\
21,4\end{array}$ & $\begin{array}{l}54 \\
22\end{array}$ & $\begin{array}{c}75 \\
78,6\end{array}$ & 0,14 & 1 & 0,7073 \\
\hline
\end{tabular}


Tabela 6 - Número e proporção de variáveis qualitativas entre grupos de crianças com ausência e presença de $A$. lumbricoides, segundo exame coproparasitológico de 100 crianças do bairro Santo André, Vitória-ES, 2004.

\begin{tabular}{|c|c|c|c|c|c|c|c|c|}
\hline & & \multicolumn{2}{|c|}{ Positivo } & \multicolumn{2}{|c|}{ Negätivo } & \multicolumn{3}{|c|}{ Teste Qui-Quadrado } \\
\hline & & $\mathbf{N}$ & $\%$ & $\mathbf{N}$ & $\%$ & Valor & gl & p-valor \\
\hline $\begin{array}{c}\text { Frequenta } \\
\text { creche }\end{array}$ & $\begin{array}{l}\text { sim } \\
\text { não }\end{array}$ & $\begin{array}{c}12 \\
3\end{array}$ & $\begin{array}{l}17,6 \\
9,4\end{array}$ & $\begin{array}{l}56 \\
29\end{array}$ & $\begin{array}{l}82,3 \\
90,6\end{array}$ & 1,25 & 1 & 0,2629 \\
\hline $\begin{array}{l}\text { Último } \\
\text { tratamento } \\
\text { em meses }\end{array}$ & $\begin{array}{l}0 \mid-3 \\
3 \mid-6 \\
6 \mid-12 \\
12 \mid-24 \\
\text { nunca } \\
\text { não sabe }\end{array}$ & $\begin{array}{l}2 \\
3 \\
1 \\
3 \\
4 \\
2\end{array}$ & $\begin{array}{c}13,3 \\
37,5 \\
5,6 \\
20 \\
10,3 \\
40 \\
\end{array}$ & $\begin{array}{c}13 \\
5 \\
17 \\
12 \\
35 \\
3 \\
\end{array}$ & $\begin{array}{c}86,6 \\
62,5 \\
94,4 \\
80 \\
89,7 \\
60 \\
\end{array}$ & 4,95 & 4 & 0,2923 \\
\hline $\begin{array}{c}\text { Tipo de } \\
\text { tratamento }\end{array}$ & $\begin{array}{l}\text { automedicaçăo } \\
\text { receita médica } \\
\text { nunca }\end{array}$ & $\begin{array}{l}5 \\
5 \\
5\end{array}$ & $\begin{array}{l}27,8 \\
11,9 \\
12,5\end{array}$ & $\begin{array}{l}13 \\
37 \\
35\end{array}$ & $\begin{array}{l}72,2 \\
88,1 \\
87,5\end{array}$ & 2,47 & 2 & 0,2911 \\
\hline $\begin{array}{l}\text { Come } \\
\text { alface }\end{array}$ & $\begin{array}{l}\text { sim } \\
\text { năo }\end{array}$ & $\begin{array}{c}13 \\
2\end{array}$ & $\begin{array}{c}18,1 \\
7,1\end{array}$ & $\begin{array}{l}59 \\
26\end{array}$ & $\begin{array}{l}81,9 \\
92,9\end{array}$ & 2,13 & 1 & 0,1444 \\
\hline
\end{tabular}

Os pés de alface apresentaram $23,3 \%$ de positividade, sendo 0 Strongyloides sp e a Giardia sp os parasitas mais prevalentes (Tabelas 7 e 8). 
Tabela 7 - Pés de alface contaminados segundo exame parasitológico em pés de alface adquiridos no comércio do bairro Santo André, Vitória-ES, 2004.

\begin{tabular}{ccc}
\hline Variáveis & Número & $\%$ \\
\hline Positivos & 14 & 23,3 \\
Negativos & 46 & 76,7 \\
\hline TOTAL & 60 & 100 \\
\hline
\end{tabular}

Tabela 8 - Freqüência dos espécimes parasitários observados nas amostras de alface contaminadas segundo exame parasitológico em pés de alface adquiridos no comércio do bairro Santo André, Vitória-ES, 2004.

\begin{tabular}{lcc}
\hline \multicolumn{1}{c}{$\begin{array}{c}\text { Espécimes } \\
\text { Parasitários }\end{array}$} & Número & $\%$ \\
\hline Strongyloides sp & 6 & 42,8 \\
Giardia sp & 5 & 35,7 \\
Ascaris sp & 2 & 14,3 \\
Trichuris sp & 1 & 7,2 \\
\hline \multicolumn{1}{c}{ TOTAL } & 14 & 100 \\
\hline
\end{tabular}




\section{DISCUSSĀO}

A prevalência de enteroparasitoses em crianças de 1 a 4 anos do bairro Santo André, Vitória-ES, enfocada neste estudo, foi de $40 \%$, enquanto MACEDO e col. (1998) realizando o mesmo tipo de estudo em crianças de favelas do Rio de Janeiro-RJ, registraram $55 \%$.

No presente estudo a $G$. duodenalis foi o parasita mais comum com 24 (24\%) casos positivos, seguido pelo A. lumbricoides com 15 (15\%), T. trichiura com $5(5 \%)$, E. histolytica $3(3 \%)$, S. stercoralis $3(3 \%), H$. nana $1(1 \%)$, ancilostomídeos 1 (1\%) e E. vermicularis 1 (1\%). MACEDO e col. (1998), encontraram G. lamblia $(25,3 \%)$, T. trichiura $(19,3 \%)$, E. histolytica (3\%), S. stercoralis $(2 \%), H$. nana $(1,4 \%)$, ancilostomideos $(0,3 \%)$ e $E$. vermicularis $(0,2 \%)$. Nota-se que a posição dos espécimes nas duas pesquisas foi semelhante.

\subsection{Enteroparasitoses e creche}

A rotina de freqüentar creche apresentou relação estatística para enteroparasitoses $(p=0,01)$. Convém citar que GUIGNARD e col. (2000), num estudo de prevalência de enteroparasitoses em crianças de orfanatos da província de Córdoba na Argentina, analisaram 386 amostras fecais encontrando $85 \%$ de positividade, sendo o segundo parasita mais comum a $G$. lamblia, contribuindo com $23 \%$ dos casos e CARARETO e col, em 1999, observaram que em Mirassol-SP, a prevalência de crianças contaminadas foi maior em creche pública que em privada, sendo a $G$. intestinalis o parasita mais comum. Entretanto no presente trabalho não foi possível estabelecer 
relação estatística entre giardíase e creche para um nível de significância de $5 \%(p=0,05)$, porém para um nivel de significância de $7 \%(p=0,07)$, a relação passa a ser positiva.

Deve ser salientado que $68 \%$ das crianças estudadas freqüentam creche (Tabela 10), o que torna esse ambiente perigoso, principalmente com relação a parasitos intestinais como a $G$. duodenalis. Convém atentar que as situaçōes de risco que ocorrem nas creches não foram objetivo desse estudo, mas deveriam ser pesquisadas em outro momento, pois a presença maciça das crianças nesse ambiente e a correlação estatística para enteroparasitoses sugere esse local como sendo de grande risco para as doenças enteroparasitárias.

\subsection{Consideraçōes sobre a giardiase}

Com relação à nomenclatura da Giardia, THOMPSON e col. (2000), referem que $o$ desenvolvimento da análise molecular desse agente parasitário indica a existência de cinco espécies de Giardia, dessas somente a Giardia duodenalis causa infecção humana. Convém citar que ROCHA e col. em 2003, pesquisaram as características moleculares da $G$. duodenalis de humanos no Brasil. Entretanto para THOMPSON e col. (2000), essa espécie também pode ser encontrada parasitando mamiferos silvestres e domésticos como cães e gatos, sugerindo que esses animais possam estar envolvidos na epidemiologia da giardiase do homem. Os autores sugerem que o nome cientifico Giardia duodenalis deve ser adotado nos casos de giardiase humana. 
A análise da revisão bibliográfica e dos resultados dessa pesquisa indica que a ampliação das obras de saneamento básico reduziu, ainda que de forma insatisfatória, a prevalência das infecçōes parasitárias intestinais, entretanto a G. duodenalis manteve uma elevada prevalência em relação aos demais parasitas. Esse protozoário mantém suas taxas de infecção através da contaminação da água, dos alimentos e do ambiente beneficiando-se da deficiência do saneamento básico e da higiene pessoal.

No bairro estudado foi observado como situação de perigo para infecção por enteroparasitas e especialmente por $G$. duodenalis o elevado número de hortaliças contaminadas sem vigilância sistematizada, a freqüente e tolerada defecação no solo por parte das crianças o que contamina todo o ambiente podendo ser agravada pela deficiência de higiene pessoal, fase oral das crianças e pelo instinto de reposição de minerais através de hábitos geofágicos. Também podem estar atuando como situação de perigo a ausência do filtro doméstico o que foi verificado em $30 \%$ das residências, a já comentada freqüência à creche e possivelmente o contato com animais domésticos contaminados, uma vez que durante o trabalho de campo foi observada elevada quantidade de animais domésticos no ambiente peri e intradomiciliar.

\subsection{Geofagia e ascaridiase}

Foi observada relação estatística entre o hábito de defecar no solo e a contaminação por parasitoses intestinais $(p=0,007)$ apesar de mais de $99 \%$ dos domicilios disporem de banheiro. O hábito das crianças de defecar no solo foi comumente observado durante o trabalho de campo e verificado em $29 \%$ das 
crianças. A importância do uso correto do banheiro foi demonstrada por HOSAIN e col. (2003), que estudando o impacto do uso da latrina e da educação em saúde em crianças entre 5 e 13 anos de idade em Bangladesh, estabeleceu relação do uso da latrina como fator de proteção contra as parasitoses intestinais.

A defecação no ambiente favorece a contaminação por parasitas intestinais, pois parasitas como o A lumbricoides necessitam da passagem pelo solo para se tornarem infectantes.

Relacionando geofagia e geo-helmintoses, OLCEM e col. (2002), pesquisaram a reinfecção por helmintos em 1161 escolares de 10 a 14 anos de idade da zona rural de Kwazulu-Natal na África do Sul. Os pesquisadores verificaram que após recente tratamento com albendazol o A. lumbricoides foi o parasita mais comum, com $28 \%$ de prevalência entre as crianças que realizaram ingestão de solo e $19 \%$ entre as crianças que não ingeriram solo. De forma semelhante, NAISH e col. (2004), pesquisando geo-helmintoses em 204 crianças carentes de uma vila de pescadores no sul da Índia, verificaram $92,6 \%$ de prevalência geral, sendo que a grande maioria estava multiparasitada. Os parasitas mais comuns foram o A. lumbricoides $(91 \%), \circ T$. trichiura $(72 \%)$ e os ancilostomídeos $(54 \%)$.

Essas pesquisas indicam que o $A$ lumbricoides foi responsável pelo maior número de casos de geo-helmintoses. Vale comentar que esse parasito se beneficia de vários veiculos de contaminação, lembrando que NEVES 
(1995), cita que em determinadas condições de umidade e sombreamento o ovo do $A$. lumbricoides pode permanecer infectante por até 1 ano.

\subsection{Consideraçōes sobre a ascaridiase}

Nesta pesquisa o $A$. lumbricoides foi o segundo enteroparasita mais prevalente. Esse parasita apesar de ser facilmente diagnosticado, tratado e reconhecido como agente de infecção comum na faixa etária estudada, alcançou prevalência de $15 \%$. O A. lumbricoides além de exercer ação espoliante, tóxica, irritante e obstrutiva também pode gerar graves complicaçăo na sua forma errática, assim como mostram VALENTINE e col. (2001) que pesquisaram três pacientes portadores de complicações secundárias à ascaridíase. Observam respectivamente: abscesso periapendiceal, pneumonia e cólica vesicular por coledocolitiase obstrutiva. Os autores afirmam ainda que essas complicaçōes podem ser facilmente evitadas com a administração profilática do anti-helmintico albendazole em dose única. Também KLOTZ e col. (2003), afirmam que o A. lumbricoides é responsável pela morbidade e mortalidade relacionadas à obstrução intestinal e complicações hepatobiliares e pancreáticas. Os pesquisadores ainda citam que as infecções maciças são responsáveis por casos de mal-nutrição e que a fonte de infecção comumente está relacionada à ingestão de hortaliças contaminadas e hábitos geofágicos. COTA e col. (2004) também referem o A. lumbricoides como importante fator de risco associado à subnutrição, contribuindo para a carência de sais minerais. $O$ instinto de reposição dos componentes minerais através da 
geofagia também poderia estar contribuindo para a alta prevalência dessa helmintose na população estudada.

\subsection{Enteroparasitoses e idade}

Analisando enteroparasitoses e idade, os resultados concordam com os de MONTEIRO e col. (1988) e MACEDO e col. (1998), que afirmam que, quanto mais idade apresenta a criança, maior é o risco de contaminação, pois crianças com mais idade dispőem menos da amamentação que é livre de parasitas e interagem mais com o ambiente ficando mais tempo expostas à infecção. MACEDO e REY, em 2000, afirmaram que o aleitamento materno atua como fator de proteção contra infecção por parasitas intestinais. AKISU e col. (2004), pesquisando o efeito do aleitamento materno sobre as enteroparasitoses, observaram que o colostro e o leite humano maduro têm efeito letal significante sobre a $E$. histolytica. FERREIRA e COSTA (1995) pesquisando parasitas intestinais em 56 bebês em lactação de um berçário mantido pela Universidade Federal Uberlândia-MG observaram um percentual de positividade geral de $23 \%$, sendo $18 \%$ de ancilostomideos e $5 \%$ de $G$. lamblia, contudo, não encontraram nenhum caso de $E$. histolytica.

\subsection{Enteroparasitoses e tratamento}

Houve relação estatística entre parasitados e o último tratamento em meses, quanto mais recente o tratamento maior a positividade. Essa constatação foi inesperada, entretanto observou-se que $25 \%$ dos individuos positivos fizeram automedicação. Empiricamente, individuos que fazem automedicação para parasitoses intestinais geralmente utilizam vermífugos que 
não possuem ação sobre protozoários como a $G$. duodenalis que foi o parasita mais comum. Todavia não foi estabelecida relação entre infecção por $G$. duodenalis e automedicação.

O número de crianças que nunca fizeram tratamento algum para parasitoses foi $40(40 \%)$, sendo que dessas $28 \%$ estavam negativas. Um número significativamente grande de indivíduos negativos dentre os que nunca fizeram tratamento pode ser atribuido ao fator idade (Tabela 2). Crianças muito jovens estão menos expostas à parasitas, podendo ainda não terem sido submetidas a tratamento.

Analisando casos positivos e negativos em relação a utilização de medicação por receita médica (Tabela 4) foi verificado $59,5 \%$ de negativos dentre os que se submeteram a essa forma de tratamento. $O$ achado sugere que o tratamento medicamentoso agiu como fator de proteção para as parasitoses intestinais, entretanto não foi possivel estabelecer nenhum tipo de relação entre parasitoses intestinais e forma de tratamento, além disso, foi observado um alto número de parasitados dentre os que já haviam sido tratados, evidenciando a necessidade de diagnóstico e tratamento precisos e periódicos.

Para melhor compreensão do efeito do tratamento medicamentoso antiparasitário vale citar outros autores.

RAJESWARI e col. (1994) afirmam que o albendazole administrado em dose única de $400 \mathrm{mg}$ foi efetivo para $100 \%$ dos casos de $A$. lumbricoides, mas foi pouco efetivo contra o T. trichiura. 
ALBONICO e col, em 1997, analisando a eficácia do tratamento medicamentoso com mebendazole $500 \mathrm{mg}$ (Janssen Pharmaceutica) e albendazole 400mg (SmithKline Beecham) contra nematodos intestinais, pesquisaram 2294 crianças entre 6 e 12 anos de idade de Zanzibar na Tanzânia. Verificaram que ambas as drogas eram altamente efetivas contra $A$. lumbricoides, com taxas de cura superiores a $97 \%$. As taxas de cura para o $T$. trichiura foram baixas, mas o mebendazole era significativamente melhor que o albendazole para esse parasita.

TAYLOR e col. (1999) observaram que o tratamento medicamentoso com albendazole, realizado em Bangladesh era mais efetivo para o controle dos helmintos do que apenas educação em saúde.

SEBASTIAN e SANTI, em 2000, em estudo realizado no Equador verificaram que as taxas de infecção por $A$. lumbricoides e $T$. trichiura permaneceram reduzidas por até 9 meses após 0 tratamento com antiparasitários, no entanto apresentaram-se novamente elevadas 18 meses após o tratamento.

SINUON e col. (2003) pesquisando tratamento para parasitoses intestinais durante um ano e meio, em escolares de áreas rurais e semi-rurais do Camboja, observaram que a taxa de infecção foi reduzida para $1 / 3$ do número habitual utilizando mebendazole $500 \mathrm{mg}$ a cada 6 meses.

E relevante comentar que dentre as 40 crianças positivas deste estudo, 21 permaneciam contaminadas mesmo após terem sido submetidas à consulta 
médica a menos de 3 meses, o que sugere algum tipo de falha no diagnóstico ou tratamento para mais de $50 \%$ das crianças parasitadas.

\subsection{Enteroparasitoses e educação em saúde}

O bairro Santo André possui $99,9 \%$ dos domicilios abastecidos por água tratada pela CESAN - Companhia Espírito Santense de Saneamento, 98,5\% com coleta semanal de lixo, 99,1\% com captação de esgoto, todas as ruas com calçamento e acesso garantido a consulta médica à toda populaçāo, mas mesmo com essas medidas de saneamento, urbanização e de ação de saúde, no bairro foi encontrado alto número de parasitados, sugerindo que obras de engenharia sanitária, urbanização e formas convencionais de diagnóstico e tratamento sejam insuficientes para o controle aceitável das parasitoses intestinais. Pesquisas indicam que a educação em saúde contribue de forma efetiva no controle das parasitoses intestinais, assim como mostra PASTRANA e col. (1994), que no México, desenvolveram práticas de educação em saúde com aproximadamente 9 mil escolares e suas mães, verificando que após um ano a taxa de consultas por parasitoses intestinais reduziu de 53 para 12 consultas por 1000 habitantes, havendo redução de 3,1 para 1,8 casos de ascaridiase por 1000 habitantes e reduziu-se as doses de albendazol de 8503 para 3412 doses anuais, concluindo que a educação em saúde direcionada às parasitoses intestinais reduz a demanda de atenção médica e a utilização de medicação antiparasitária. Nesse sentido TAYLOR e col. (2003) pesquisando a fixação de informações sobre parasitoses intestinais em quatro áreas da zona rural de Bangladesh na Índia, verificaram que a população adquiriu, de modo 
significativo, mais informações sobre os fatores de risco para as parasitoses intestinais após o desenvolvimento de campanhas de educação em saúde.

\subsection{Contaminação da água tratada}

A ausência de filtro nas residências também apresentou relação estatística para infeç̧ão por parasitas intestinais (Tabela 14). Crianças que não dispõem de filtro no domicilio apresentaram maior risco para desenvolver parasitasoses intestinais. Entretanto não foi possivel estabelecer relação estatistica do consumo da água sem tratamento domiciliar com nenhum parasita em particular. Não se pode atribuir o elevado número de casos a possiveis falhas no tratamento da água nas centrais de abastecimento, embora esta contaminação possa se dar nos mais diversos niveis da rede, pois esta variável não foi estudada. Convém citar que COELHO e col. (2001), avaliaram a presença de formas transmissiveis de enteroparasitas em água tratada retirada de reservatórios domiciliares, observando $0,7 \%$ das amostras contaminadas.

\subsection{Enteroparasitoses e hortaliças}

Pesquisando a contaminaçäo das hortaliças foram analisadas 60 amostras de alface comercializadas na feira livre e supermercado da localidade. Foram pesquisadas amostras aleatórias dentre as formas crespa e lisa (pés de alface), cuja prevalência quanto à forma não foi importante, uma vez que somente $4(6,5 \%)$ amostras eram da forma lisa e estavam todas negativos. Foram verificadas $14(23,3 \%)$ amostras positivas para alguma forma 
parasitária intestinal, sendo que $6(10 \%)$ por Strongyloides sp, $5(8,3 \%)$ por Giardia sp, $2(3,3 \%)$ por Ascaris sp e $1(1,6 \%)$ por Trichuris sp (Tabela 14).

TAKAYANAGUI e col. (2000), pesquisando a prevalência de enteroparasitas diretamente nas hortas de Ribeirão Preto-SP, observam $13,1 \%$ de amostras contaminadas. Em outro estudo COELHO e col. (2001), encontrou $3,9 \%$ das amostras contaminadas. Segundo o mesmo autor, mesmo depois de lavadas as hortaliças mantinham $33 \%$ das amostras contaminadas $(1,3 \%)$, constatando que a lavagem não garantiu a ausência de contaminação nas hortaliças. Também indicando redução de formas parasitárias em hortaliças após lavagem KOSAN e col. (2004), estudando a prevalência de ovos de helmintos em 203 amostras não lavadas e 406 amostras lavadas de vegetais normalmente consumidos crus na cidade de Ankara na Turquia, observaram que somente as hortaliças não lavadas estavam contaminadas.

Contudo nesta pesquisa não foi possivel estabelecer relação entre o hábito de comer alface e infecção por parasitos intestinais. Entretanto, dentre as familias que oferecem alface para suas crianças, o que totaliza $72 \%$ da populaçāo estudada, $32 \%$ estavam contaminadas, desses somente $5(5 \%)$ relataram hábito de não lavar alface folha por folha, sendo que dentre estes, todos estavam parasitados, estabelecendo relaçāo estatistica para $p=0,002$ (Tabela 8). É importante considerar que o número de positivos relacionados com a forma de lavar alface foi pequeno.

Indicando possiveis formas de contaminação das hortaliças OLIVEIRA (1991), GUILHERME e col. (1999), TAKAYANAGUI e col. (2000) e 
GUIMARÃES e col. (2003), citaram que a água utilizada na irrigação constitui importante fonte de contaminação para hortaliças, sendo que OLIVEIRA (1991) ressalta que a aspersão de água nas hortaliças pode contribuir para o aumento do período de viabilidade das formas infectantes, mantendo a umidade para os vegetais e para as formas parasitárias. 0 mesmo autor ainda cita que o enxágüe das hortaliças em um mesmo recipiente de água, além de manter a umidade do vegetal contamina a água que contamina outras hortaliças até então limpas. Convém informar que tanto a aspersão como o enxágüe foram observados com freqüência na feira livre da localidade.

Vale acrescentar que soluçöes sanitizantes pouca ou nenhuma açāo exercem sobre os parasitos, sendo necessária à ação mecânica sobre os alimentos consumidos crus, a fim de que as formas infectantes sejam reduzidas em número, uma vez que são dificeis de serem destruidas nesse tipo de alimento. 


\section{CONCLUSÕES}

No bairro estudado:

$\checkmark$ Foram constatadas $40 \%$ de crianças parasitadas, sendo que a maior prevalência ocorreu nas faixas etárias mais elevadas ( 3 e 4 anos de idade);

$\checkmark$ Os parasitas mais freqüentes nas crianças foram respectivamente: $G$. duodenalis (24\%), A. lumbricoides (15\%), T. trichiura (5\%), E. histolytica (3\%), S. stercoralis (3\%), $H$. nana (1\%), ancilostomídeos (1\%) e $E$. vermicularis (1\%);

$\checkmark$ A prevalência de parasitas intestinais observada dentre as alfaces (crespa e lisa) comercializadas na feira livre e supermercado da região foi de $23,3 \%$, o que evidencia contaminação durante a produção, transporte ou comercialização final do produto;

$\checkmark$ A prevalência dos espécimes parasitários encontrados nas amostras de alface foi respectivamente: Strongyloides sp $10 \%$, Giardia sp $8,3 \%$, Ascaris sp 3,3\% e Trichuris sp 1,6\%.

$\checkmark$ A alface não lavada folha por folha antes do consumo pode ser uma forma de manutenção dos altos níveis de contaminação parasitária na comunidade, uma vez que todos os indivíduos que não tinham este hábito repetitivo estavam contaminados;

$\checkmark$ Freqüentar creches apresentou relação estatística para infecção por enteroparasitas, principalmente G. duodenalis; 
$\checkmark$ A defecação no solo contribuiu para a prevalência das parasitoses intestinais, sendo um hábito freqüente entre as crianças estudadas;

$\checkmark$ Muitas crianças apresentaram-se infectadas mesmo após consulta médica nos últimos 3 meses;

$\checkmark$ Observou-se que mesmo com disponibilidade de água tratada, captação do esgoto, coleta do lixo, ruas pavimentadas e atendimento médico a comunidade manteve significativo número de parasitados. 


\section{RECOMENDAÇŌES}

Os resultados indicam que o controle das doenças parasitárias intestinais, bem como a prevenção de cada uma delas, além das ações em saneamento exigem conhecimento dos fenômenos ecológicos, sociais e culturais que envolvem o homem, pois os parasitas perpetuam seu ciclo biológico não somente em função do veículo hídrico, mas também, dos hábitos e costumes de uma população. Beber água fervida ou filtrada, lavar os alimentos crus, cozinhar cames, lavar as mãos antes de comer e após utilizar o sanitário, defecar sempre na latrina e andar calçado são algumas medidas que contribuem para o controle dessas infecçōes. Para complementar as açōes de saúde faz-se necessário uma efetiva rede ambulatorial para diagnóstico, tratamento e orientação da população. Ainda deve-se controlar a contaminação dos alimentos durante a cadeia de produção, transporte e comercialização.

No bairro estudado variáveis como: defecação no solo, hábito de freqüentar creche, não lavar a alface folha por folha e ausência de filtro no domicilio, apresentaram relação positiva para parasitoses intestinais. Esses resultados sugerem que ações de educação em saúde focadas no local correto da defecação, acompanhamento e análise da rotina das creches detectando fatores de risco, salientar a importância de lavar corretamente os alimentos consumidos crus (alface) e o tratamento adequado da água no domicilio contribuiriam para a redução do número de casos positivos no bairro estudado.

O bairro apesar de saneado e urbanizado continha um alto número de parasitados sugerindo que o saneamento básico e as atuais formas de açōes 
na saúde pública são insuficientes para o controle aceitável das enteroparasitoses devendo ser complementadas por programas especificos de vigilância sanitária e educação em saúde voltados para o controle das parasitoses intestinais. 


\section{REFERĖNCIAS}

Ahmed AK, Malik B, Shaheen B, Yasmeen G, Dar JB, Mona AK, Gulab S, Ayub M. Frequency of intestinal parasitic infestation in children of 5-12 years of age in Abbottabad. J Ayub Med Coll Abbottabad. 2003;15(2):28-30.

Akisu C, Aksoy U, Cetin H, Ustun S, Akisu M. Effect of human milk and colostrum on Entamoeba histolytica. World J Gastroenterol. 2004;10(5):741-2.

Albonico M, Chwaya HM, Montresor A, Stolfzfus RJ, Tielsch JM, Alawi KS, Savioli L. Parasitic infections in Pemba Island school children. East Afr Med J. 1994; 74(5):294-8.

Almeida A. Lugar de toda pobreza. (VHS). ES-Brasil. Rede Gazeta de comunicações, 1983.

Almeida IS. Estudo transversal de prevalência de Giardia lamblia e outros parasitas intestinais no bairro Nossa Senhora de Fátima-Planaltina, DF. Brasília Méd. 1991; 28:16-9.

Baldo ET; Belizario WY; De Leon WU; Kong HH; Chung DI - Infection status of intestinal parasites in children living in residential institutions in Metro Manila, the Philippines. Korean J Parasitol. 2004; 42(2):67-70.

Borda CE; Rea MJ; Rosa JR; Maidana C. Intestinal parasitism in San Cayetano, Corrientes, Argentina. Bull Pan Am Health Organ. 1996; 30(3):22733.

Bundy DAP, Cooper ES. Trichuris is not trivial. Parasitol Today. 1998; 4:301-7. 
Carareto CMA, Cristante SFV, Machado RC, Marcari EL. Giardiase e helmintiases em crianças de creches e escolas de $1^{\circ}$ e $2^{\circ}$ graus (públicas e privadas) da cidade de Mirassol-SP, Brasil. Rev Soc Brás Méd Trop.1999; 32:1-11.

Castro C, Molina $L Z$. As parasitoses intestinais na população do município de Mambaí em dois períodos distintos, 1974 e 1986. Brasilia med. 1998; 25(1/4):5-7.

Coelho LMPS, Oliveira SM, Milmam MHSA, Karasawa AA, Santos RP. Detecção de formas transmissíveis de enteroparasitas na água e nas hortaliças consumidas em comunidades escolares de Sorocaba, São Paulo, Brasil. Rev Soc Bras Méd Trop. 2001; 34:479-482.

Cota LQ, Valencia ME, Crompton DWT, Phillips S, Hagan P, Camacho SPD, et all. Prevalence and intensity of intestinal parasitic infections in relation to nutritional status in Mexican schoolchildren. Transac Royal Soc Trop Med Hyg. 2004; article in press. unw.elsevierhealth.com/jornals/trst

Crompton DWT. The prevalence of Ascariasis. Parasitol Today. 1998; 4:163-9.

Enekwechi LC; Azubike CN. Survey of the prevalence of intestinal parasites in children of primary school age. West Afr J Med. 1994; 13(4):227-30.

Kosan E, Gonenc B, Sarimehmetoglu, Aycicek H. Prevalence of helminth eggs on raw vegetables used for salads. Food Control. 2004; article in press. unw.elsevier.com/locate/foodcont 
Ferreira BM, Costa CJM. Intestinal parasites in children aged 4-12 months attending day-care centers of Federal University-Uberlândia-MG. J Pediatr (Rio J).1995; 71(4):219-22.

Ferreira CB, Marçal JO. Enteroparasitoses em escolares do distrito de Martinésia, Uberlândia, MG: Um estudo piloto. Rev Soc Brás Méd Trop. 1997; $30(5): 1-8$.

Fernandes PMG, Mendoza GL, Agostinetti DA, Salinas LCA, Taralli M. Infecção por parasitoses intestinais em crianças de 0 a 24 meses. Rev. Paul. Pediatr. $1988 ; 21: 57-59$.

Ferreira P; Lima MR; Oliveira FB; Pereira ML; Ramos LB; Marçal MG; CostaCruz JM. Occurrence of intestinal parasites and commensal organisms among schoolchildren living in a 'landless farm workers' settlement in Campo FloridoMG, Brasil. Rev Soc Bras Med Trop. 2003; 36(1):109-11.

França AL, Zanotti AR, Rocha A, Pereira DD, Andriolo ME, Bonissem KM, et al. Projeto São Pedro: levantamento para compor o plano estratégico de saúde do municipio de Vitória. Vitória-ES. Pref. Municipal de Vitória 1995.

Gamboa MI, Basualdo JA, Córdoba MA, Pezzani BC, Minvielle MC, Lahitte HB. Distribution of intestinal parasitoses in relation to environmental and sociocultural parameters in La Plata, Argentina. J Helminthol. 2003; 77(1):1520.

Gbakima AA, Sherpard M, White PT. Intestinal helminth infections in rural school children in Njala, Sierra Leone. East Afr Med J. 1994; 71(12):792-6. 
Gil A C, Métodos e Técnicas de Pesquisa Social. 5 ed. São Paulo: Atlas, 1999.

Gross R, The impact of improvement of water and sanitation facilities on diarrhea and intestinal parasites: A brasilian experience with children in two lowincome urban communities. Rev Saúde Pública, 1989; 23:214-20.

Guignard S, Arienti H, Freyre L, Lujan $H$, Rubinstein $H$. Prevalence of enteroparasites in a residence for children in the Córdoba Province, Argentina. Eur J Epidemiol. 2000; 16(3):287-93.

Guilherme ALF, Araújo SM. Prevalência de enteroparasitas em horticultores e hortaliças da Feira do Produtor de Maringá-PR, Brasil. Rev Soc Bras Med Trop. 1999; 32(4):405-11.

Guimarães AM, Alves EGL, Figueiredo HCP, Costa GM, Rodrigues LS. Freqüência de enteroparasitoses em amostras de alface (Lactuca sativa) comercializadas em Lavras, Minas Gerais. Rev Soc Bras Med Trop. 2003; $36(5): 621-623$.

Hachich, EM. Avaliação da presença dos protozoários Giardia sp e Cryptosporidium sp em águas superficiais destinadas a captação e tratamento para consumo humano no estado de São Paulo. São Paulo; 2002. [Tese de Doutorado - Faculdade de Saúde Pública da USP].

Hosain GM, Saha S, Begum A. Impact of sanitation and health education on intestinal parasite infection among primary school aged children of Sherpur, Bangladesh. Trop Doct. 2003; 33(3):139-43. 
Jorge MHPM, Laurenti R, Gotlieb SD. A Saúde no Brasil: análise do período de 1996 a 1999. Brasilia DF. Organização Pan-americana de Saúde/Opas 2001.

Kim BJ; Ock MS; Chung DI; Yong TS; Lee KJ. The intestinal parasite infection status of inhabitants in the Roxas city, The Philippines. Korean J Parasitol. $2003 ; 41(2): 113-5$

Klotz F, Baye PSM, Wade B. Ascaridiose. EMC-Pédiatrie. 2003; 1:186-197.

krombauer AL, Krombauer FL, Antunes HBN. Influência sócio-econômica sobre as parasitoses intestinais. Pesqui Méd. 1997; 30:9-14.

Lima CR, Limpeza pública de Vitória. Vitória: prefeitura municipal de Vitória; 2002.

Love J. A Locomotiva: São Paulo na Federação Brasileira 1889-1937. Rio de Janeiro: Paz e Terra; 1982.

Macedo CLM; Rey L. Maternal and child intestinal parasitism and breastfeeding. Rev Soc Bras Med Trop. 2000; 33(4):371-5.

Macedo LMC, Silva JRM, Silva RR, Oliveira LM, Vianna MSR. Enteroparasitoses em pré-escolares de comunidades favelizadas da cidade do Rio de Janeiro-RJ, Brasil. Cad de Saúde Pública. 1998; 14:851-855.

Machado ER, Cruz JMC. Strongyloides stercoralis and other enteroparasites in children at Uberlândia city, state of Minas Gerais, Brazil. Mem Inst Oswaldo Cruz. 1998; 93(2):161-164. 
Martins, G. Impacto do Saneamento Básico na Saúde Pública. São Paulo; 2001. [Tese de Doutorado - Faculdade de Saúde Pública da USP].

Marzochi MCA. Estudo dos fatores envolvidos na disseminação dos enteroparasitas (Estudo da contaminação de verduras e solo de hortas na cidade de Ribeirão Preto, São Paulo, Br. Rev Inst Méd Trop S Paulo. 1997; 20:148-55.

Mesquita VCL, Bastos OMP, Serra CMB, Uchoa CMA. Contaminação por enteroparasitas em hortaliças comercializadas nas cidades de Niterói e Rio de Janeiro, Brasil. Rev Soc Brás Méd Trop. 1999; 32(4):1-5.

Monteiro, CA, Chieffi PP, Benício MHA, Dias DRM, Torres DMACV, Mangini ACS. Estudo das condiçōes de saúde das crianças do município de São Paulo. Rev Saúde Pública. 1988; 22:8-15.

Moraes LRS, Cancio JÁ, Cairncross S. Impact of drainage and sewerage on intestinal nematode infections in poor urban áreas in Salvador, Brasil. Transa Royal Soc Trop Med Hygi. 2004; 98:197-204.

Morales EEM, Sánchez PHJ, García GMM, Vargas MG, Méndez SJD, Pérez RM. Intestinal parasites in children, in highly deprived areas in the border region of Chiapas, Mexico. Rev Salud Pub Mex. 2003; 45(5):379-88.

Morrone FB, Reis C, Carneiro JA. Study of enteropasites infection frequency and chenoterapeutic agents used in pediatric patients in a community living in Porto Alegre-RS, Brasil. Rev Inst Méd Trop. 2004; 46:77-80. 
Muniz PT; Ferreira MU; Ferreira CS; Conde WL; Monteiro CA. Intestinal parasitic infections in young children in Sāo Paulo, Brazil: prevalences, temporal trends and associations with physical growth. Ann Trop Med Parasitol. 2002; 96(5):503-12.

Naish S, McCarthy J, Williams GM. Prevalence, intensity and fators for soiltransmitted helminth infection in a South Indian Fishing village. Acta tropica. $2004 ; 91: 177-187$

Neghme A. Silva, R. Ecologia del parasitismo em el hombre. Bol Ofic Sanit Panamer.1971; 70: 313-23.

Neves DP. Parasitologia Humana. $9^{a}$ Edição. Rio de Janeiro: Atheneu; 1995.

Nunes AGA. Os argonautas do mangue: uma etnografia visual dos caranguejeiros do município de Vitória - ES. Campinas; 1998. (Dissertação de mestrado - Universidade de Campinas).

Olcem A, Saathoff E, Geissler KPW. Geophagy and its association with geohelminth infection in rural schoolchildren from northern Kwazulu-Natal, South Africa. Transac Royal Soc Trop Med Hyg. 2002; 96:485-490.

Oliveira CA. Estudo da ocorrência de enteroparasitoses intestinais em hortaliças comercializadas na regiāo metropolitana de São Paulo. São Paulo; 1991: [Dissertação de Mestrado - Faculdade de Saúde Pública da USP]. 
Pastrana EH, Abarca VMC, Herrera GR, Espinoza MM. Impacto da lá educación antiparasitária en la demanda de educación médica. Rev. Méd IMSS (México). 1994; 32(4):339-41.

Pawlowski ZS, Schad GA, Stott GJ. Infección y anemia por anquilostomas: Possibilidade de prevención y lucha. Ginebra: Organización Mundial de la Salud; 1992.

Pereira J, Carlesso DB, Maruza M. Frequência de parasitas intestinais em uma amostragem da populaçäo da Grande Vitória-ES, Brasil. Rev Farm Bioquim. $1987 ; 8(1 / 2): 37-45$.

Pérez AC, Ariza AC, Ubeda OJM, Guevara BDC, Rojas AM, Lozano SC. Epidemiology of children's intestinal parasitism in the Guadalquivir Valley, Spain. Rev Esp Salud Publica. 1997; 71(6):547-52.

Rajeswari B, Sinniah B, Hussein H. Socio-economic factors associated with intestinal parasites among children living in Gombak, Malaysia. Asia Pac J Public Health. 1994; 7(1):21-5.

Rey L. Parasitologia. $2^{\mathrm{a}}$ Edição. Rio de Janeiro: Guanabara Koogan; 1991.

Rocha MO, Costa CA, Mello RT, Moreira MCC. Estudo comparativo da prevalência de parasitoses intestinais em escolares de Belo Horizonte-MG. Rev bras anal clin. $1994 ; 26(4): 127-9$.

Rocha OM, Gomes MA, Costa AO, Furst C, Silva EF. Molecular characterization of brazilian human G.iárdia duodenalis isolates using 
isoenzyme and random amplified polymorphic DNA analysis. Diag Microb Infect Dis. 2003; 46:273-278.

Santi S, e Sebastian SM. Control of intestinal helminthes in schoolchildren in Low-Napo, Ecuador: impact of a two-year chemotherapy program. Rev. Soc Bras Méd Trop. 2000; 33:69-73.

Sinuon M; Anantaphruti MT; Socheat D. Intestinal helminthic infections in schoolchildren in Cambodia. Southeast Asian J Trop Med Public Health. 2003; 34(2):254-8.

Straka S, Hudecková H, Mad'ar R, Baska T. Intestinal parasites in children from the Turiec region in long-term monitoring. How should we proceed with further preventive parasitologic examinations. Epidemiol Mikrobiol Imunol. 2001; $50(1): 22-5$.

Takayanagui OM, Febrônio LHP, Bergamine AM, Okino MHT, Silva AAMC, Santiago $R$ et al. Fiscalização de hortas de verduras do município de Ribeirão Preto, SP. Rev Soc Bras Med Trop. 2000; 33:169-174.

Taylor CGMN, Karim R, Karim E, Aktar S, Ahmed T, Montanari RM. The costeffectiveness of health education in improving knowledge and awareness about intestinal parasites in rural Bangladesh. Economics and human biology. $2003 ; 1 ; 321-330$.

Taylor MCG, Alam M, Montanari RM, Karim R, Ahmed T, Karim E, Akhtar S. A study of the cost effectiveness of selective health interventions for the control of intestinal parasites in rural Bangladesh. J Parasitol. 1999; 85(1):6-11. 
Téllez A, Morales W, Rivera T, Meyer E, Leiva B, Linder E. Prevalence of intestinal parasites in the human population of León, Nicaragua. Acta Trop. 1997; 66(3):119-25.

Teodoro U, Casavechia MTG, Dias MLG, Falavigna DLM, Pedroni SM, Arroio LMA. Perfil epidemiológico das parasitoses intestinais no municipio de Maringá, Paraná, Brasil. Ciênc Cult. 1988; 40:698-702.

Thompson RCA, Hopkins RM, Homan WL. Nomenclature and genetic groupings of Giardia infecting mammals. Parasitology Today. 2000; 16(5):210213.

Valentine CC, Hoffner RJ, Henderson SO. Three common presentations of ascariasis infection in an urban emergency department. J Emerg Med. 2001; 20(2):135-139. 
ANEXOS 


\section{FAESA - Faculdade de Saúde \\ Projeto de Extensão em Parasitoses Intestinais \\ Prof. Wilson Denadai}

Autorizo a realização de exames parasitológicos de fezes em material coletado de um ou mais membros da minha família e ainda a utilização dos dados da entrevista e os resultados dos exames para pesquisa, uma vez que, não sejam citados os nomes dos colaboradores em nenhum resultado e ainda que seja realizado o tratamento para os casos positivos.

$\mathrm{Em}, \ldots . . . . . . . / 04$

Responsável 


\section{USP - Universidade de São Paulo \\ Projeto de Parasitoses Intestinais \\ Prof: Wilson Denadai}

1 - Há quanto tempo a criança foi submetida à última consulta médica?

2 - A criança já fez exame de fezes?

( ) sim

( ) não

3 - Há quanto tempo aproximadamente foi feito o último exame de fezes?

4 - A criança já tomou remédio para verminose?

( ) sim

( ) não

( ) outros

5 - Há aproximadamente quanto tempo tomou remédio para verminose?

6 - Qual a origem do remédio para verminose?

( ) receitado pelo médico.

( ) indicado pelo balconista da farmácia.

( ) comprou por conta própria.

( ) fez remédio caseiro.

() outros. 
7 - Alguma vez a criança fez cocô em locais como?

( ) No chão da rua.

Há aproximadamente quanto tempo foi à última vez que fez cocô no chão?

( ) No chão do quintal.

Há aproximadamente quanto tempo foi à última vez que fez cocô no quintal.

( ) Outro local que não seja o vaso sanitário do banheiro.

Qual?.

8 - Para onde vai o cocó do peniquinho ou da fralda?

( ) para o lixo.

( ) para o vaso sanitário do banheiro.

( ) quintal.

( ) rua.

() outros.

9-A criança fica em creche?

( ) sim.

( ) não.

10 - A criança come alface?

( ) sim.

( ) não.

11 - A alface é lavada?

( ) sim.

( ) não.

12 - Como a alface è lavada?

( ) folha por folha.

( ) todo o "pé" de uma vez.

( ) outros.

13 - Qual o tipo de casa em que vocé mora?

( ) lajota/bloco.

( ) madeira.

( ) outros 
14 - A casa tem banheiro com vaso sanitário?

( ) sim.

( ) não.

( ) outros

15 - De onde vem a água de beber?

( ) CESAN

( ) poço/cacimba

( ) poço artesiano

( ) outros.

16 - Tem filtro em casa?

( ) sim.

( ) não.

17 - Para onde vai o esgoto?

( ) fossa.

( ) captação de esgoto.

( ) vala aberta.

( ) outros. 


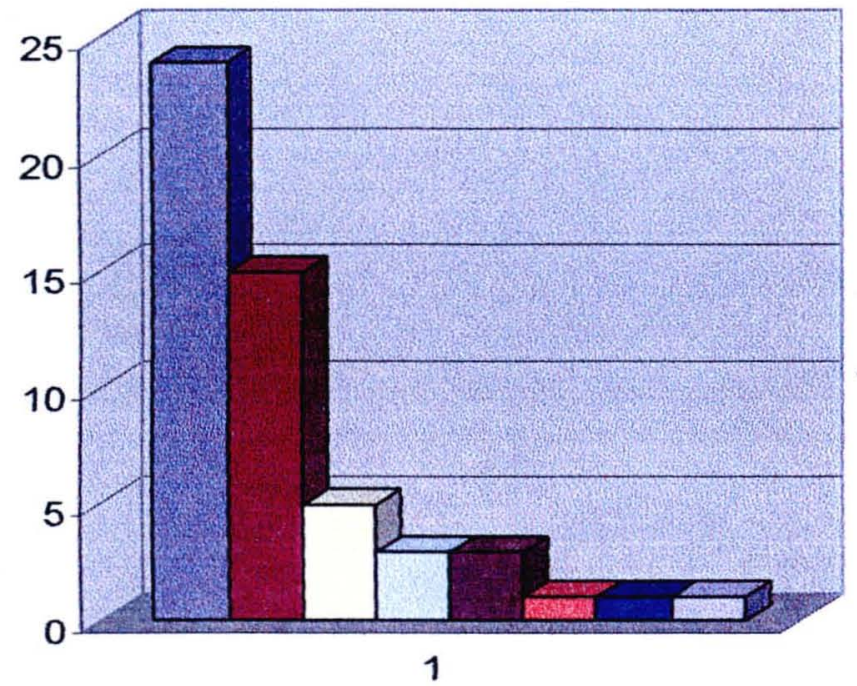

$\square$ Giardia duodenalis

Ascaris lumbricoides

$\square$ Trichiuris trichiura

$\square$ Entamoeba histolytica

- Strongyloides stercoralis

Ancylostoma spp

Enterobius vermicularis

$\square$ Hymenoleps nana

Figura 8 - Número de parasitados e espécime parasitário segundo exame coproparasitológico em 100 crianças de Santo André, Vitória-ES, 2004.

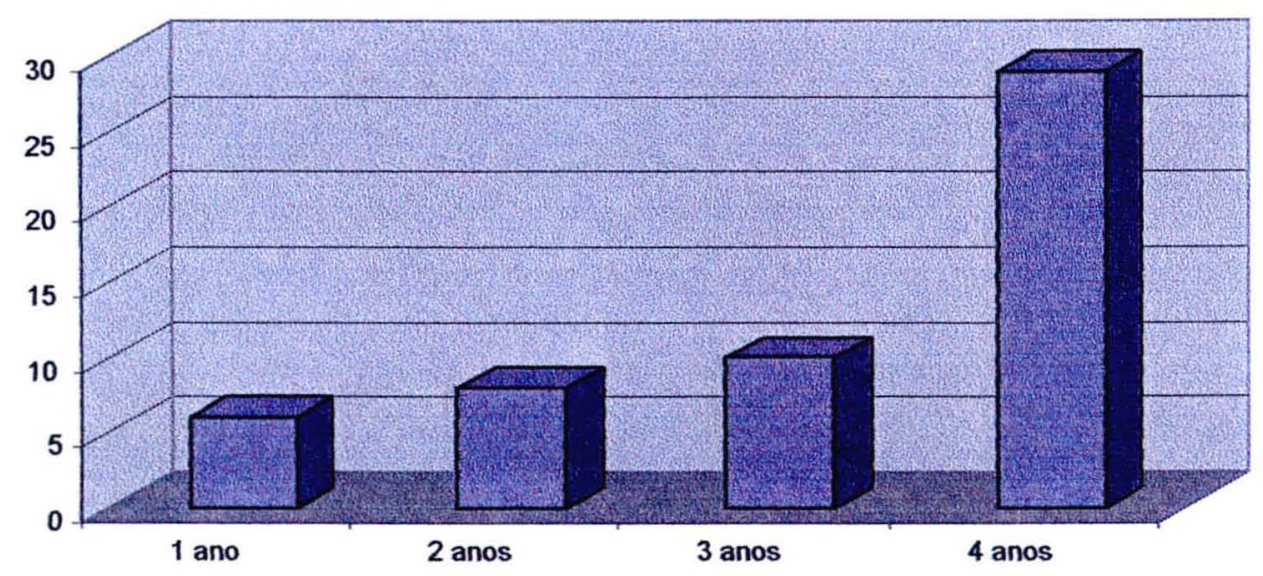

Figura 9 - Número de parasitados e idade em anos segundo exame coproparasitológico em 100 crianças de Santo André, VitóriaES, 2004. 


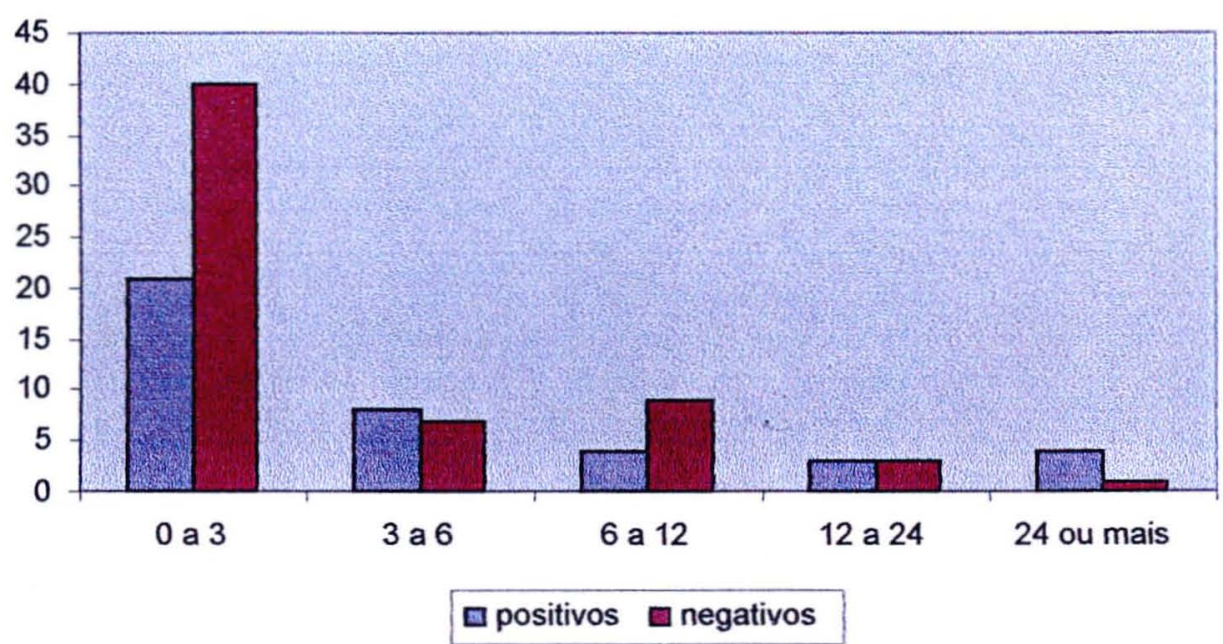

Figura 10 - Casos positivos, negativos e última consulta médica em meses segundo exame coproparasitológico em 100 crianças de Santo André, Vitória-ES, 2004.

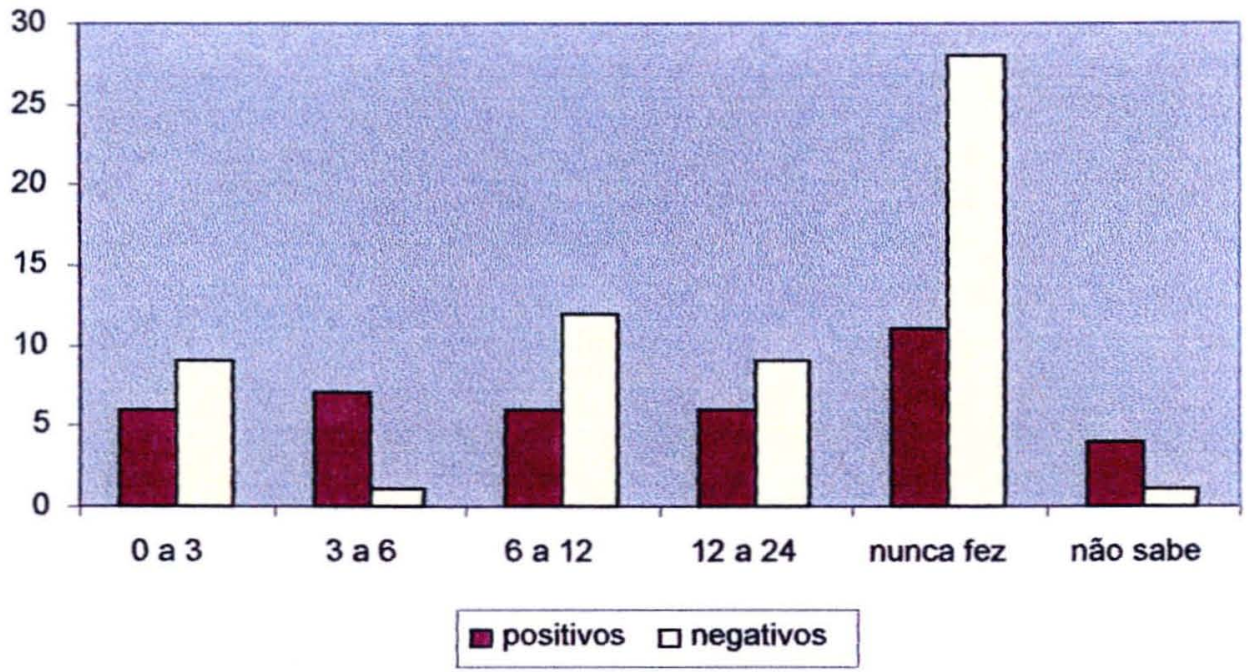

Figura 11 - Casos positivos, negativos e último tratamento medicamentoso em meses segundo exame coproparasitológico em 100 crianças de Santo André, Vitória-ES, 2004. 


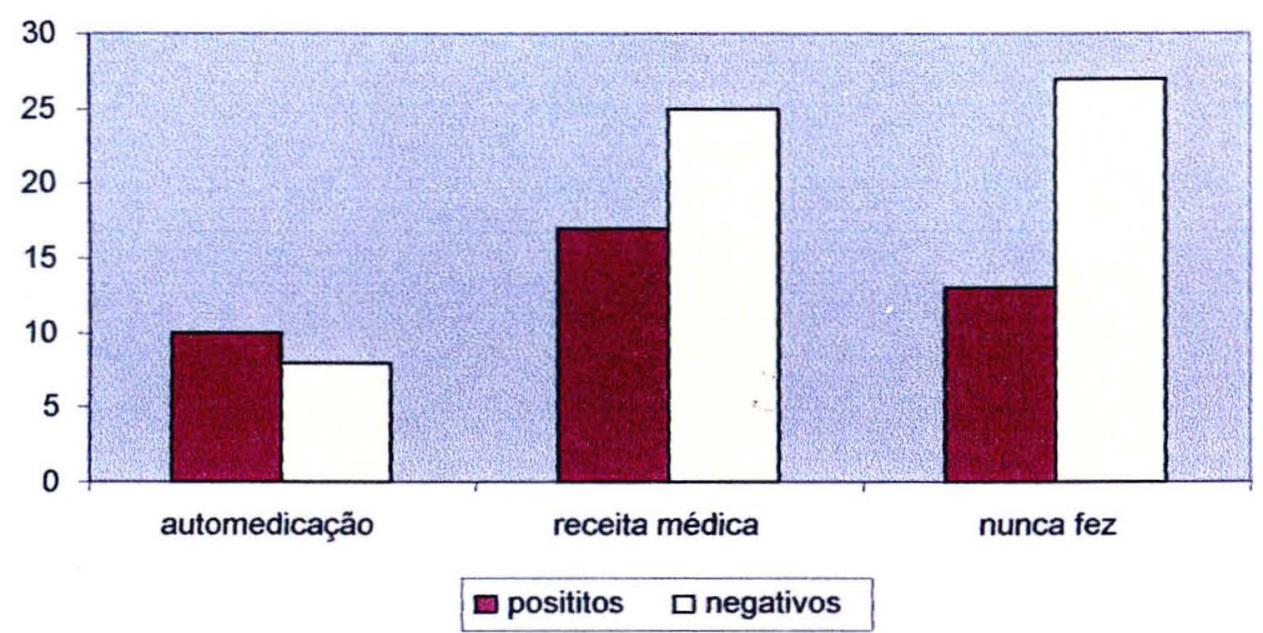

Figura 12 - Casos positivos, negativos e forma de tratamento segundo exame coproparasitológico em 100 crianças de Santo André, Vitória-ES, 2004.

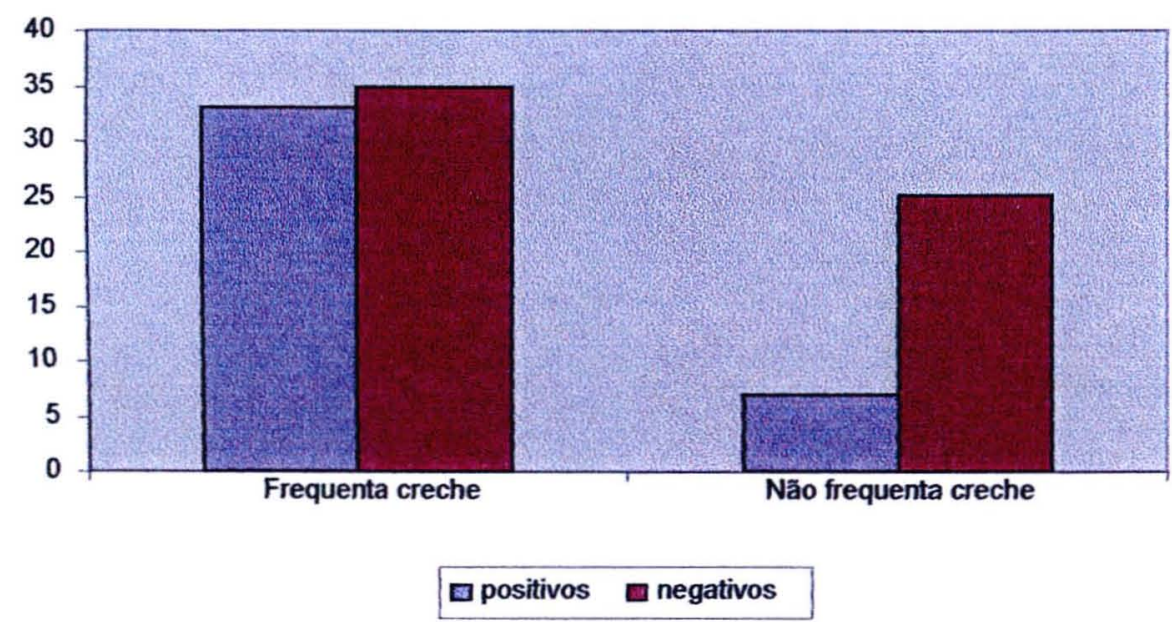

Figura 13 - Casos positivos, negativos e freqüência em creche segundo exame coproparasitológico em 100 crianças de Santo André, Vitória-ES, 2004 


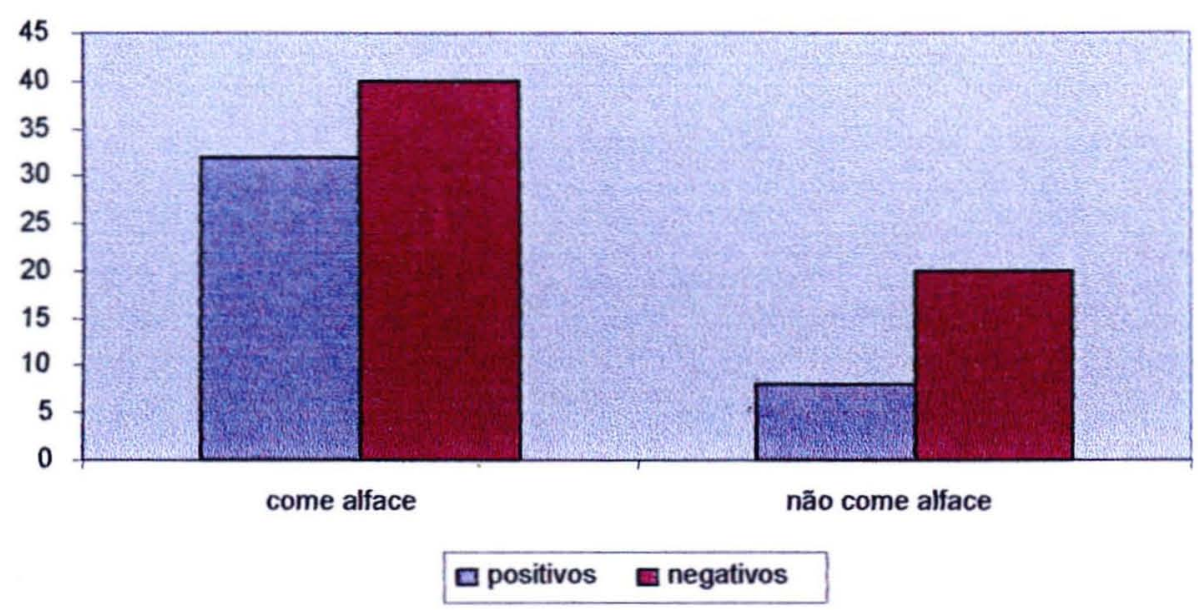

Figura 14 - Casos positivos, negativos e hábito de comer alface segundo exame coproparasitológico em 100 crianças de Santo André, Vitória-ES, 2004.

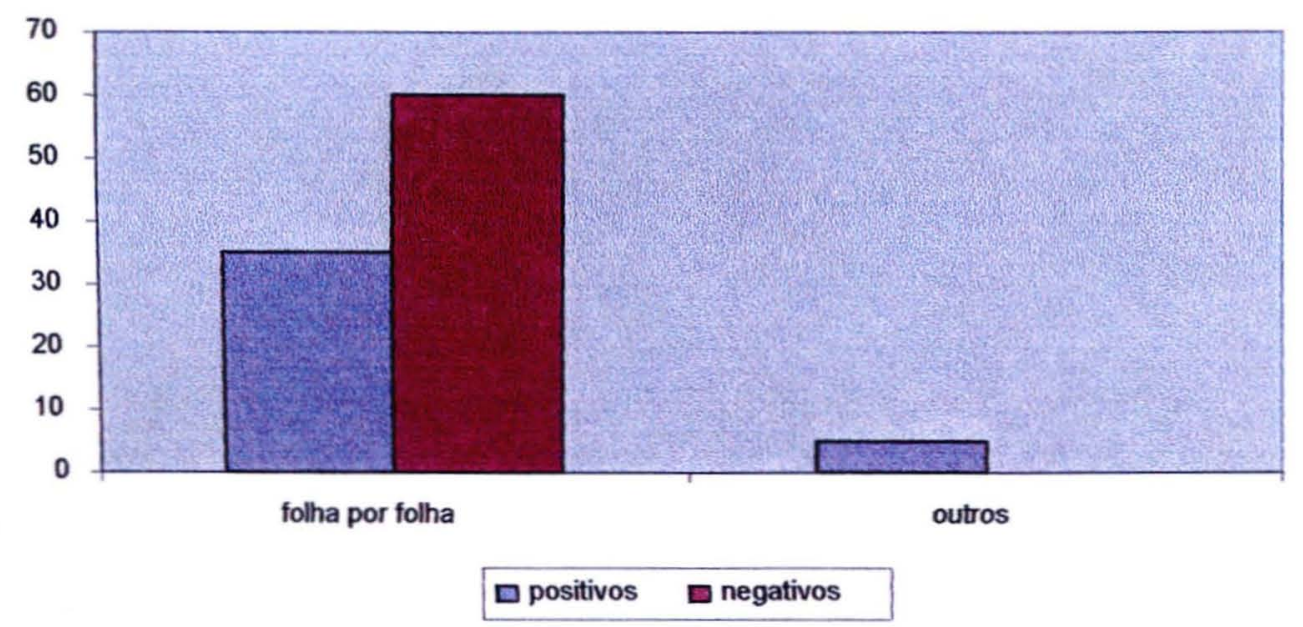

Figura 15 - Casos positivos, negativos e forma de lavar alface segundo exame coproparasitológico em 100 crianças de Santo André, Vitória-ES, 2004. 


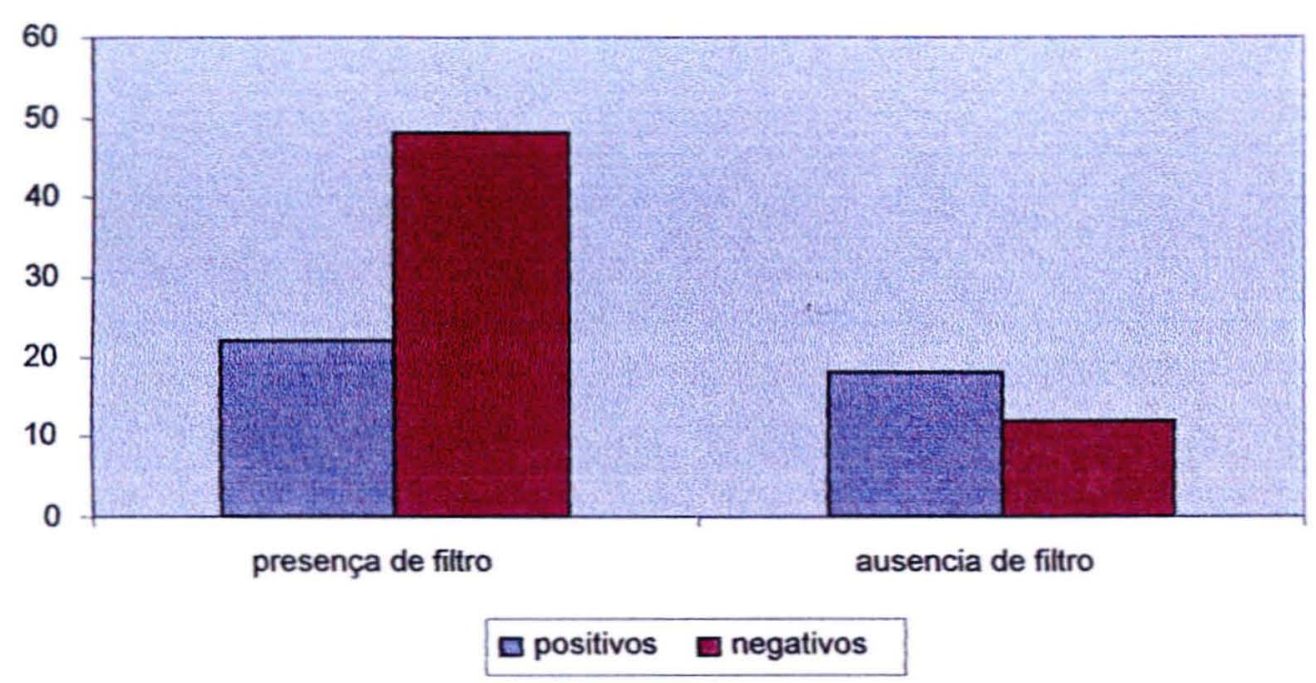

Figura 16 - Casos positivos, negativos e presença e ausência de filtro no domicilio segundo exame coproparasitológico em 100 crianças de Santo André, Vitória-ES, 2004. 